\section{(A) Check for updates}

Cite this: Polym. Chem., 2020, 11 6343

Received 31st July 2020

Accepted 8th September 2020

DOI: 10.1039/d0py01097a

rsc.li/polymers

\title{
Rational synthesis of epoxy-functional spheres, worms and vesicles by RAFT aqueous emulsion polymerisation of glycidyl methacrylate $\uparrow$
}

\author{
Fiona L. Hatton, (D) * Matthew J. Derry (D) $\S$ and Steven P. Armes (D)*
}

\begin{abstract}
The rational synthesis of epoxy-functional diblock copolymer nano-objects has been achieved via RAFT aqueous emulsion polymerisation of glycidyl methacrylate (GlyMA; aqueous solubility $22 \mathrm{~g} \mathrm{dm}^{-3}$ at $50^{\circ} \mathrm{C}$ ) by utilising relatively mild conditions $\left(\mathrm{pH} \mathrm{7,50}{ }^{\circ} \mathrm{C}\right)$ to preserve the epoxy groups. High monomer conversions were achieved within $1 \mathrm{~h}$ when using a poly (glycerol monomethacrylate) chain transfer agent with a mean degree of polymerisation (DP) of 28, with GPC analysis indicating relatively narrow molecular weight distributions $\left(M_{w} / M_{n}<1.40\right)$ when targeting PGlyMA DPs up to 80. A phase diagram was constructed to identify the synthesis conditions required to access pure spheres, worms or vesicles. Transmission electron microscopy, dynamic light scattering and small-angle X-ray scattering (SAXS) studies indicated the formation of well-defined worms and vesicles when targeting relatively long PGlyMA blocks. These epoxy-functional nano-objects were derivatised via epoxy-thiol chemistry by reaction with L-cysteine in aqueous solution. Finally, an in situ SAXS study was conducted during the RAFT aqueous emulsion polymerisation of GlyMA at $50{ }^{\circ} \mathrm{C}$ to examine the nucleation and size evolution of PGMA $48^{-}$ $\mathrm{PGlyMA}_{100}$ diblock copolymer spheres using a bespoke stirrable reaction cell.
\end{abstract}

\section{Introduction}

Block copolymer self-assembly in solution can produce various types of organic nanoparticles that in principle can offer a range of potential applications. ${ }^{1}$ Traditionally, self-assembly has been achieved via post-polymerisation processing by lowering the degree of solvation for one of the blocks, typically by adding a non-solvent or by adjusting the temperature. ${ }^{2,3}$ Spheres or vesicles tend to be the most commonly observed morphologies, but worms, rods, ${ }^{4}$ toroids,${ }^{5}$ bicontinuous structures or lamellae have also been reported. ${ }^{6}$ Block copolymer worms can be used as viscosity modifiers or gelators, ${ }^{7}$ while

Dainton Building, Department of Chemistry, University of Sheffield, Brook Hill, Sheffield, South Yorkshire, S3 7HF, UK. E-mail:f.hatton@lboro.ac.uk,

s.p.armes@sheffield.ac.uk

$\dagger$ Electronic supplementary information (ESI) available: Kinetic data for RAFT solution polymerisation of GMA in ethanol; kinetic data for RAFT aqueous emulsion polymerisation of GlyMA, summary of copolymer characterisation data, GPC curves for selected diblock copolymers, SAXS patterns, summary tables of SAXS parameters from model fittings, elemental microanalytical data, and DLS analysis before and after L-cysteine derivatisation, further details of the SAXS models. See DOI: 10.1039/d0py01097a

\$Current address: Department of Materials, Loughborough University, Loughborough, LE11 3TU, UK.

$\S$ Current address: Aston Institute of Materials Research, Aston University, Birmingham, B4 7ET, UK. block copolymer vesicles can be used for the encapsulation of nanoparticles, proteins or enzymes. ${ }^{8-10}$

Polymerisation-induced self-assembly (PISA) involves chain extension of a soluble homopolymer using a suitable second monomer that, once polymerised, becomes insoluble in the reaction media, thereby driving in situ self-assembly to form diblock copolymer nanoparticles. ${ }^{11-13}$ Reversible additionfragmentation chain transfer (RAFT) polymerisation ${ }^{14}$ has proven to be a particularly popular technique for PISA syntheses, owing to its versatility in enabling the facile preparation of a wide range of functional diblock copolymers. ${ }^{15,16}$ Hawkett and co-workers reported the first example of PISA via RAFT aqueous emulsion polymerisation. ${ }^{17,18}$ Other notable pioneers in this field included Charleux, ${ }^{19}$ Rieger, ${ }^{20}$ D'Agosto and Lansalot. $^{21,22}$ Since these seminal studies, PISA has been extended to include RAFT dispersion polymerisation conducted in water, ${ }^{23}$ polar organic solvents ${ }^{24}$ and non-polar media. ${ }^{25}$ For such formulations, many pseudo-phase diagrams (or morphology maps) have been constructed that enable the reproducible targeting of pure spheres, worms or vesicles. ${ }^{26-29}$ The formation of spheres is generally favored by using relatively long steric stabiliser blocks and/or by working at lower copolymer concentrations. ${ }^{26,30}$ In contrast, vesicles are typically obtained at higher copolymer concentrations when utilising relatively short steric stabiliser blocks and targeting long core-forming blocks. Generally, the phase space occupied by 
pure worms is relatively narrow hence this is usually the most elusive morphology. ${ }^{31,32}$ Although there are many literature examples of kinetically-trapped spheres, ${ }^{26,33-35}$ it is usually possible to prepare well-defined worms or vesicles for most RAFT dispersion polymerisations, given sufficient synthetic effort. $^{36-39}$

Although some notable exceptions are known in the literature, ${ }^{40-49}$ the majority of RAFT aqueous emulsion polymerisation formulations only yield kinetically-trapped spheres when utilising various water-immiscible monomers such as styrene, ${ }^{50,51}$ methyl methacrylate ${ }^{52,53} n$-butyl methacrylate, ${ }^{54,55}$ $n$-butyl acrylate, ${ }^{17,18,56}$ benzyl methacrylate ${ }^{57}$ or 2,2,2-trifluoroethyl methacrylate. ${ }^{58,59}$ Charleux and co-workers reported the first PISA synthesis of block copolymer 'nanofibers' (or worms) via RAFT aqueous emulsion polymerisation when chainextending a water-soluble statistical copolymer precursor comprising poly(ethylene glycol) methyl ether acrylate (PEGA) and acrylic acid with styrene. ${ }^{40,41}$ Well-defined spheres, worms and vesicles could be obtained using the analogous all-methacrylic statistical copolymer as a stabiliser block. ${ }^{60,61}$ In addition, D'Agosto and co-workers recently reported that copolymerisation of a relatively small amount of PEGA with $\mathrm{N}$-acryloylmorpholine also resulted in the formation of vesicles with polystyrene membranes under certain conditions. ${ }^{43}$ Furthermore, Hawkett and coworkers reported the synthesis of a range of block copolymer nano-objects using either amphiphilic $\mathrm{AB}$ diblock or ABA triblock copolymers as steric stabiliser precursors. ${ }^{45,46}$ It is currently not understood why this rather small subset of RAFT aqueous emulsion polymerisation formulations can provide access to higher order morphologies, whereas the majority of such PISA syntheses only yield kinetically-trapped spheres. However, it is perhaps noteworthy that most of the counter-examples involve anionic statistical copolymer stabilisers, for which self-assembly is likely to be affected by both solution $\mathrm{pH}$ and ionic strength.

Recently, we reported that chain extension of a poly (methacrylic acid) stabiliser via RAFT aqueous emulsion polymerisation of 4-hydroxybutyl methacrylate (HBMA) at $\mathrm{pH} 5$ produced an unusual 'monkey nut' morphology. ${ }^{62}$ We hypothesised that the relatively high aqueous solubility of HBMA $\left(20 \mathrm{~g} \mathrm{dm}^{-3}\right.$ at the synthesis temperature of $70^{\circ} \mathrm{C}$ ) enabled more effective plasticisation of the core-forming block, which in turn facilitated fusion of the monomer-swollen spheres to produce 'monkey nuts', rather than kinetically-trapped spheres. Similarly, 2-methoxyethyl methacrylate (MOEMA) exhibits an aqueous solubility of $19.6 \mathrm{~g} \mathrm{dm}^{-3}$ at $70{ }^{\circ} \mathrm{C}$ and also enables access to worms and vesicles as well as spheres. ${ }^{47}$ Glycidyl methacrylate (GlyMA) has a comparable aqueous solubility to that of HBMA and MOEMA. ${ }^{63}$ However, in our initial studies we found that the RAFT aqueous emulsion polymerisation of GlyMA using a water-soluble poly(glycerol monomethacrylate) (PGMA) macromolecular chain transfer agent (macro-CTA) only produced sterically-stabilised PGMA-PGlyMA spheres. ${ }^{64}$ Subsequently, we reported that PGMA-PGlyMA worms could be prepared using a highly convenient one-pot methodology provided that the steric stabiliser block was rela- tively short (DP $=25) .{ }^{48}$ In both cases, it was essential to use relatively mild conditions ( $\mathrm{pH} 4-7,50{ }^{\circ} \mathrm{C}$ ) and short reaction times $(1 \mathrm{~h})$ to minimise ring-opening of the pendent epoxy groups by reaction with water. The resulting spheres and worms could be derivatised using epoxy-amine chemistry. ${ }^{65-67}$ In closely related work, Tan and co-workers recently reported that the RAFT aqueous emulsion polymerisation of GlyMA at 25-50 ${ }^{\circ} \mathrm{C}$ using a low-temperature redox initiator also enables preservation of epoxy functionality. ${ }^{49}$ More specifically, when targeting a PGlyMA DP of 150 using a non-ionic water-soluble precursor, spheres were obtained when conducting GlyMA polymerisations at $20{ }^{\circ} \mathrm{C}$, spheres and worms were formed at $37^{\circ} \mathrm{C}$ and vesicles were produced at $50^{\circ} \mathrm{C}$. Few other literature reports of RAFT aqueous emulsion polymerisation of GlyMA exist and are limited to seeded emulsion polymerisations using photo-PISA ${ }^{68}$ and enzyme-initiated PISA. ${ }^{69}$

Herein we report the synthesis of epoxy-functional diblock copolymer spheres, worms and vesicles via RAFT aqueous emulsion polymerisation of GlyMA under mild conditions $\left(50{ }^{\circ} \mathrm{C}, \mathrm{pH} 7\right)$. A pseudo-phase diagram is constructed to ensure reproducible targeting of these nano-objects and to examine the effect of varying the copolymer concentration on the final copolymer morphology. Selected examples of spheres, worms and vesicles are characterised using small angle X-ray scattering (SAXS). We demonstrate that aqueous dispersions of epoxy-functional diblock copolymer worms can be derivatised via epoxy-thiol chemistry by reaction with L-cysteine, which influences their aqueous electrophoretic behaviour. Finally, the RAFT aqueous emulsion polymerisation of GlyMA was monitored in situ using SAXS to monitor the nucleation and growth of $\mathrm{PGMA}_{48}-\mathrm{PGlyMA}_{100}$ diblock copolymer spheres.

\section{Experimental}

\section{Materials}

Glycerol monomethacrylate (GMA) was donated by GEO Specialty Chemicals (Hythe, UK) and used without further purification. Glycidyl methacrylate (GlyMA; 97\%), 4,4'-azobis(4cyanopentanoic acid) (ACVA; 99\%), 2,2'-azobisisobutyronitrile (AIBN; 98\%), hexane (HPLC grade; $\geq 97 \%$ ), sodium hydroxide $(\mathrm{NaOH} ; 98 \%)$, and $\mathrm{L}$-cysteine $(97 \%)$ were purchased from Sigma-Aldrich (UK) and were used as received. 2,2'-Azobis[2-(2imidazolin-2-yl)propane]dihydrochloride (VA-044; $\geq 97 \%$ ). 2-Cyano-2-propyl dithiobenzoate (CPDB) was purchased from Strem Chemicals Ltd (Cambridge, UK) and was used as received. Deuterated solvents were purchased from Goss Scientific Instruments Ltd (Cheshire, UK). All other solvents and concentrated hydrochloric acid (32\%) were purchased from Fisher Scientific (Loughborough, UK) and used as received. Deionised water was used for all experiments.

\section{Characterisation}

${ }^{1} \mathbf{H}$ NMR spectroscopy. Spectra were recorded in either $\mathrm{CDCl}_{3}, \mathrm{CD}_{3} \mathrm{OD}$ or $d_{6}$-DMSO at $20{ }^{\circ} \mathrm{C}$ using a Bruker Avance III HD $400 \mathrm{MHz}$ spectrometer and averaged over 16 scans. 
Dynamic light scattering (DLS). A Malvern Zetasizer NanoZS instrument was used to determine the $z$-average diameter $\left(D_{z}\right)$ and polydispersity index (PDI) using the cumulants method. All measurements were performed on $0.1 \%$ copolymer dispersions, either in deionised water using disposable plastic cuvettes or in DMF using quartz cuvettes. All data were averaged over three consecutive runs.

Aqueous electrophoresis. Zeta potentials were determined as a function of solution $\mathrm{pH}$ using a Malvern Zetasizer NanozS instrument to analyse $\sim 0.2 \% \mathrm{w} / \mathrm{w}$ aqueous dispersions of nanoparticles using $1 \mathrm{mM} \mathrm{NaCl}$ as the background electrolyte. The solution $\mathrm{pH}$ was adjusted using dilute $\mathrm{NaOH}$ or dilute $\mathrm{HCl}$ (either 0.1 or $0.01 \mathrm{M}$ ). All data were averaged over three consecutive measurements, comprising a minimum of ten runs per measurement.

Gel permeation chromatography (GPC). Copolymer molecular weight distributions $\left(M_{\mathrm{n}}, M_{\mathrm{w}}\right.$ and $M_{\mathrm{w}} / M_{\mathrm{n}}$, or $\left.\theta\right)$ were assessed using a GPC instrument comprising two Agilent PL gel $5 \mu \mathrm{m}$ Mixed-C columns and a guard column connected in series to an Agilent 1260 Infinity GPC system equipped with both refractive index and UV-visible detectors (only the refractive index detector was used in the present study) operating at $60{ }^{\circ} \mathrm{C}$. The GPC eluent was HPLC-grade DMF containing

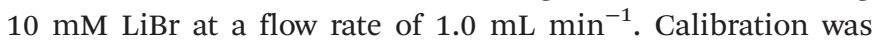
achieved using a series of ten near-monodisperse poly(methyl methacrylate) standards (ranging in $M_{\mathrm{p}}$ from 625 to $618000 \mathrm{~g}$ $\mathrm{mol}^{-1}$ ). Chromatograms were analysed using Agilent GPC/SEC software provided by the manufacturer.

Transmission electron microscopy (TEM). Copper/palladium TEM grids (Agar Scientific, UK) were coated in-house to yield a thin film of amorphous carbon. The grids were subjected to a glow discharge for $30 \mathrm{~s}$. One droplet of each dilute aqueous copolymer dispersion $(10 \mu \mathrm{L}, 0.1 \%$ solids $)$ was placed in turn on a freshly-treated grid for $1 \mathrm{~min}$ and then carefully blotted with filter paper to remove excess solution. To ensure sufficient electron contrast, a droplet of uranyl formate $(10 \mu \mathrm{L}$ of a $0.75 \% \mathrm{w} / \mathrm{w}$ solution) was placed on the sample-loaded grid for $20 \mathrm{~s}$ and then blotted to remove excess stain. Each grid was carefully dried using a vacuum hose. Imaging was performed using a FEI Tecnai Spirit 2 microscope operating at $80 \mathrm{kV}$, fitted with an Orius SC1000B camera.

Rheology. An AR-G2 rheometer equipped with a variable temperature Peltier plate and a $40 \mathrm{~mL} 2^{\circ}$ aluminium cone was used for all experiments. Percentage strain sweeps were conducted at $25{ }^{\circ} \mathrm{C}$ using a fixed angular frequency of $1.0 \mathrm{rad} \mathrm{s}^{-1}$. Angular frequency sweeps were conducted at $25{ }^{\circ} \mathrm{C}$ using a constant percentage strain of $1.0 \%$.

Helium pycnometry. The solid-state density of PGlyMA homopolymer was determined using a calibrated Micromeritics AccuPyc 1330 pycnometer at $20^{\circ} \mathrm{C}$.

Small angle X-ray scattering (SAXS). SAXS patterns were recorded for selected $1.0 \% \mathrm{w} / \mathrm{w}$ aqueous copolymer dispersions at a synchrotron source (ESRF, station ID02, Grenoble, France) using monochromatic X-ray radiation (X-ray wavelength, $\lambda=0.0995 \mathrm{~nm} ; q$ range $=0.0002$ to $0.15 \AA^{-1}$, where $q$ is the length of the scattering vector and $\theta$ is one-half of the scat- tering angle, such that $q=4 \pi \cdot \sin \theta / \lambda$ and a Ravonix MX-170HS CCD detector. A flow-through capillary set-up was used as the sample holder, with a glass capillary of $2 \mathrm{~mm}$ diameter. Scattering data were reduced using standard routines provided by the beamline and were further analysed using Irena SAS macros for Igor Pro. ${ }^{70}$ Water was used for the absolute intensity calibration. Data were recorded for $1.0 \% \mathrm{w} / \mathrm{w}$ aqueous dispersions of $\mathrm{PGMA}_{28}-\mathrm{PGlyMA}_{n}$ nano-objects originally prepared at $10 \% \mathrm{w} / \mathrm{w}, \mathrm{PGMA}_{28}-\mathrm{PGlyMA}_{n}$ nano-objects originally prepared at $20 \% \mathrm{w} / \mathrm{w}$ solids (where $n=25,40,80$ ), and the corresponding PGMA $_{28}-\mathrm{P}(\text { GlyMA-cys })_{n}$ copolymers after derivatisation where $n=25,40,80$.

For in situ SAXS experiments conducted during the RAFT aqueous emulsion polymerisation of GlyMA, SAXS patterns were collected at a synchrotron source (Diamond Light Source, station I22, Didcot, UK) using monochromatic X-ray radiation (wavelength, $\lambda=0.124 \mathrm{~nm}$, with $q$ ranging from 0.002 to $0.23 \AA^{-1}$, where $q=4 \pi \cdot \sin \theta / \lambda$ is the length of the scattering vector and $\theta$ is one-half of the scattering angle) and a $2 \mathrm{D}$ Pilatus $2 \mathrm{M}$ pixel detector (Dectris, Switzerland). The reactions were conducted as previously described ${ }^{47} \mathrm{~A}$ bespoke stirrable reaction cell was used as the sample holder, with Kapton film windows of $0.075 \mathrm{~mm}$ thickness. All reagents were purged with nitrogen gas for $30 \mathrm{~min}$ before a known volume of the deoxygenated solution was transferred into the reaction cell, which had been previously purged with nitrogen. The reaction cell was then sealed to prevent oxygen ingress before being placed in the X-ray beam along with a magnetic stirrer unit. The reaction cell was heated to $50{ }^{\circ} \mathrm{C}$ using a water circulating bath. SAXS patterns were collected every $3 \mathrm{~s}$ for $7.5 \mathrm{~min}$, then every $10 \mathrm{~s}$ for the following $27.5 \mathrm{~min}$, then every $100 \mathrm{~s}$ for $30 \mathrm{~min}$, or until no further evolution in the scattering pattern was observed. Scattering data were reduced using standard routines from the beamline and were further analysed using Irena SAS macros for Igor Pro. ${ }^{70}$ Water was used for the absolute intensity calibration. SAXS patterns were recorded for $1 \mathrm{~h}$ during the in situ synthesis of $\mathrm{PGMA}_{48}-\mathrm{PGlyMA}_{100}$ spheres at $10 \% \mathrm{w} / \mathrm{w}$. The final $\mathrm{PGMA}_{48}-\mathrm{PGlyMA}_{100}$ spheres were diluted to $1.0 \% \mathrm{w} / \mathrm{w}$ with deionised water and a SAXS pattern was recorded using a flow-through capillary set-up as the sample holder (glass capillary diameter $=2 \mathrm{~mm}$ ).

Elemental microanalysis. The carbon, hydrogen, nitrogen and sulfur microanalytical contents of freeze-dried copolymers were determined in-house using a Vario MICRO Cube CHN/S analyser (detection limit $=0.30 \%$ ).

\section{Synthesis of $\mathrm{PGMA}_{28}$ via RAFT solution polymerisation of GMA in ethanol}

The PGMA precursor used in this study was prepared via RAFT solution polymerisation of GMA in ethanol as previously described. ${ }^{26,64}$ The target mean DP was 31 and the $[\mathrm{GMA}]:[\mathrm{CPDB}]:[\mathrm{ACVA}]$ relative molar ratios were $31: 1: 0.25$. Briefly, CPDB (2.79 g, $12.6 \mathrm{mmol}$, assuming a RAFT CTA efficiency of $80 \%)$, GMA (50.0 g, $0.312 \mathrm{~mol})$ and ethanol $(80.2 \mathrm{~g}, 60 \mathrm{wt} \%)$ were weighed into a round-bottomed flask. ACVA $(0.706 \mathrm{~g}, 2.52 \mathrm{mmol})$ was added and the reaction mixture 
was cooled in an ice bath and degassed with $\mathrm{N}_{2}$ gas for $40 \mathrm{~min}$. After degassing, the flask was immersed in an oil bath set at $70{ }^{\circ} \mathrm{C}$ and the polymerisation was quenched after 160 min after the GMA conversion had reached 63\%. The crude PGMA precursor was diluted with methanol and precipitated into dichloromethane, redissolved in methanol and precipitated once more to yield the final purified $\mathrm{PGMA}_{28}$ precursor. Its mean DP was confirmed by end-group analysis using ${ }^{1} \mathrm{H}$ NMR spectroscopy in $\mathrm{CD}_{3} \mathrm{OD}$. DMF GPC analysis indicated an $M_{\mathrm{n}}$ of $8300 \mathrm{~g} \mathrm{~mol}^{-1}$ and a $\doteq$ of 1.15 .

\section{Synthesis of PGMA P $_{28}$-PGlyMA $n$ diblock copolymer nano-objects} by RAFT aqueous emulsion polymerisation

The synthesis of $\mathrm{PGMA}_{28}-\mathrm{PGlyMA}_{100}$ vesicles at $10 \% \mathrm{w} / \mathrm{w}$ using a macro-CTA/initiator ratio of 4.0 is representative of the general PISA protocol. $\mathrm{PGMA}_{28}$ macro-CTA $(0.25 \mathrm{~g}$, $0.053 \mathrm{mmol})$, and deionised water $(9.09 \mathrm{~g})$ were weighed into a sample tube. VA-044 initiator (4.30 mg, $0.013 \mathrm{mmol}$ ) was added and the $\mathrm{pH}$ was adjusted to 7.0-7.5 by addition of 0.01 M NaOH. GlyMA $(0.756 \mathrm{~g}, 5.32 \mathrm{mmol})$ was added and the reaction mixture was sealed with a rubber septum and immersed in an ice bath and degassed with $\mathrm{N}_{2}$ for $30 \mathrm{~min}$, before being placed in an oil bath set at $50{ }^{\circ} \mathrm{C}$. The polymerisation was quenched after $1 \mathrm{~h}$ by removing the reaction vessel from the oil bath and exposing its contents to air, followed by ${ }^{1} \mathrm{H}$ NMR, DLS, GPC and TEM analysis. When targeting different PGlyMA DPs the PGMA, GlyMA and VA-044 molar ratios were adjusted accordingly, maintaining a consistent solids content.

\section{Synthesis of PGlyMA by RAFT solution polymerisation}

The RAFT solution polymerisation of GlyMA was conducted in chloroform using CPDB as the RAFT agent and AIBN initiator. First, GlyMA (5.02 g, $35.2 \mathrm{mmol})$ and CPDB (0.078 g, $0.352 \mathrm{mmol}$; target $\mathrm{DP}=100$ ) were weighed into a $25 \mathrm{~mL}$ round-bottomed flask, and $\mathrm{CHCl}_{3}(7.64 \mathrm{~g})$ was added to produce a final monomer concentration of $40 \% \mathrm{w} / \mathrm{w}$. AIBN (0.012 g, $0.073 \mathrm{mmol}$; CPDB/AIBN $~ 5.0)$ was added to the reaction flask, which was immersed in an ice bath and the reaction mixture was degassed using a stream of $\mathrm{N}_{2}$ gas for $30 \mathrm{~min}$. The flask was then sealed and placed in an oil bath set at $60^{\circ} \mathrm{C}$ for $19 \mathrm{~h}$. The GlyMA polymerisation was quenched by cooling to $20{ }^{\circ} \mathrm{C}$, exposing the reaction solution to air and dilution with $\mathrm{CHCl}_{3}$. The GlyMA conversion was $95 \%$ as determined by ${ }^{1} \mathrm{H}$ NMR analysis in $\mathrm{CDCl}_{3}$. The crude PGlyMA was precipitated into excess $n$-hexane (three times), isolated by filtration and dried in a vacuum oven. Residual $n$-hexane (detected by ${ }^{1} \mathrm{H}$ NMR analysis) was removed by dissolving the purified PGlyMA in acetone and concentrating by rotary evaporation (three times), and subsequently dried using a high vacuum manifold. DMF GPC analysis indicated an $M_{\mathrm{n}}$ of $17100 \mathrm{~g} \mathrm{~mol}^{-1}$ and an $M_{\mathrm{w}} / M_{\mathrm{n}}$ of 1.17 , while helium pycnometry measurements indicated a solid-state density of $1.25 \pm 0.01 \mathrm{~g} \mathrm{~cm}^{-3}$ at $20{ }^{\circ} \mathrm{C}$.

\section{Estimation of the aqueous solubility of GlyMA at $50{ }^{\circ} \mathrm{C}$}

Deionised water $(10.0 \mathrm{~g})$ was added to a pre-weighed vial equipped with a magnetic flea. This vial was placed in an oil bath set at $50{ }^{\circ} \mathrm{C}$ and allowed to equilibrate for $20 \mathrm{~min}$. GlyMA ( $\sim 1.5 \mathrm{~g})$ was added to a pre-weighed vial and then added dropwise to the water at $50{ }^{\circ} \mathrm{C}$. After addition of each drop of GlyMA, the aqueous GlyMA mixture was stirred at $50{ }^{\circ} \mathrm{C}$ for 1-2 min. The point at which the GlyMA monomer droplets no longer fully dissolved as judged by visual inspection was noted and the vial containing GlyMA monomer was reweighed. Hence the total mass of added GlyMA was determined and its aqueous solubility at $50{ }^{\circ} \mathrm{C}$ was calculated using the following equation: aqueous solubility $=$ (mass of GlyMA/mass of water) $\times 100$. This solubility experiment was performed in triplicate and the mean aqueous solubility of GlyMA at $50{ }^{\circ} \mathrm{C}$ was found to be $2.2 \% \mathrm{w} / \mathrm{w}$, or $22.0 \mathrm{~g} \mathrm{dm}^{-3}$. This is in good agreement with data previously reported by Ratcliffe et al., who determined the aqueous solubility of GlyMA to be $1.4-1.5 \% \mathrm{w} / \mathrm{w}$ at $21^{\circ} \mathrm{C}$ and $2.4-2.5 \% \mathrm{w} / \mathrm{w}$ at $80^{\circ} \mathrm{C} .^{63}$

\section{In situ SAXS studies during RAFT aqueous emulsion polymerisation of GlyMA}

The PGMA $_{48}$ precursor used for the in situ SAXS studies was prepared according to a previous literature protocol. ${ }^{64}$ This $\mathrm{PGMA}_{48}$ precursor $(0.14 \mathrm{~g}, 0.018 \mathrm{mmol})$ was weighed into a sample tube along with deionised water (3.44 g). VA-044 initiator $(4.43 \mu \mathrm{mol} ; 0.10 \mathrm{~mL}$ of a $0.044 \mathrm{M}$ stock solution) was added and the solution $\mathrm{pH}$ was adjusted to 7.0-7.5 by adding 0.01 M NaOH. GlyMA (0.252 g, $1.77 \mathrm{mmol}$; target DP = 100) was added and the reaction mixture was then sealed with a rubber septum, immersed in an ice bath and degassed with $\mathrm{N}_{2}$ for $30 \mathrm{~min}$, before being placed in the stirrable reaction cell for the in situ SAXS experiment. After $1 \mathrm{~h}$ at $50{ }^{\circ} \mathrm{C}$, the reaction cell was removed from the beam line and the GlyMA polymerisation quenched by exposure to air. Postmortem analysis of the reaction mixture was conducted using ${ }^{1} \mathrm{H}$ NMR, DLS, GPC and TEM.

\section{Results and discussion}

Recently, we reported that the RAFT aqueous emulsion polymerisation of GlyMA using a PGMA $_{45}$ chain transfer agent only led to the formation of kinetically-trapped spheres. ${ }^{64}$ However, the aqueous solubility of GlyMA $\left(22 \mathrm{~g} \mathrm{dm}^{-3}\right.$ at $\left.50{ }^{\circ} \mathrm{C}\right)$ is comparable to that of HBMA or MOEMA, ${ }^{47,63}$ hence access to epoxy-functional worms or vesicles might be expected for such PISA formulations. Drawing on our prior experience, ${ }^{26,30,71-74}$ we decided to revisit the RAFT aqueous emulsion polymerisation of GlyMA to examine whether utilising a shorter PGMA precursor as the steric stabiliser block might enable access to such higher order morphologies.

First, a kinetic study of the RAFT solution polymerisation of GMA in ethanol using 2-cyano-2-propyl dithiobenzoate (CPDB) at $70{ }^{\circ} \mathrm{C}$ was conducted by sampling the reaction mixture periodically, see Fig. S1. $\dagger$ First-order kinetics and a linear increase in $M_{\mathrm{n}}$ with conversion were observed when targeting a degree of polymerisation (DP) of $31 .^{26}$ A dithiobenzoatecapped $\mathrm{PGMA}_{28}$ precursor $\left(M_{\mathrm{n}}=8300 \mathrm{~g} \mathrm{~mol}^{-1}, Ð=1.15\right)$ was 


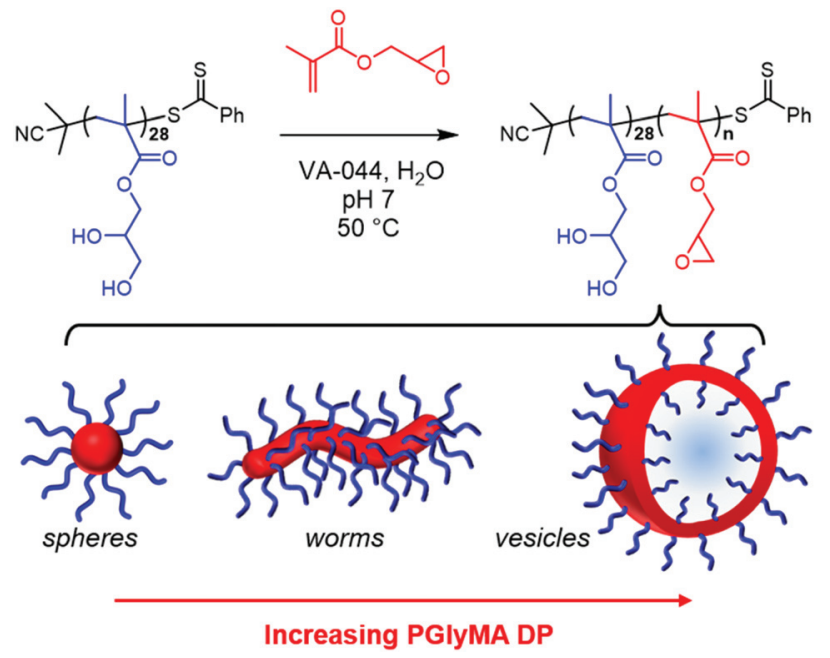

Scheme 1 Schematic representation of the RAFT aqueous emulsion polymerisation of GlyMA at $50{ }^{\circ} \mathrm{C}$ using a $\mathrm{PGMA}_{28}$ precursor at neutral $\mathrm{pH}$ to form sterically-stabilised $\mathrm{PGMA}_{28}-\mathrm{PGlyMA}_{n}$ spheres, worms or vesicles. Notably, only kinetically-trapped spheres were obtained with longer $\mathrm{PGMA}_{45}$ and $\mathrm{PGMA}_{48}$ stabiliser blocks.

prepared on a 30 gram scale and used for all subsequent RAFT aqueous emulsion polymerisation syntheses. Chain extension of this $\mathrm{PGMA}_{28}$ steric stabiliser block with GlyMA under mild conditions $\left(50{ }^{\circ} \mathrm{C}, \mathrm{pH} 7\right)$ yielded a range of epoxy-functional diblock copolymer nano-objects (see Scheme 1).

Kinetic studies confirmed that high GlyMA conversions were achieved within $1 \mathrm{~h}$ at $50^{\circ} \mathrm{C}$ with a linear evolution of $M_{\mathrm{n}}$ with conversion (see Fig. S2 $\dagger$ ). It is also worth emphasising that these polymerisations were conducted at neutral $\mathrm{pH}$ in order to prevent premature loss of the epoxy groups via ringopening side-reactions with water. Copolymer morphologies were initially assigned by transmission electron microscopy (TEM) in order to construct a phase diagram, see Fig. 1 and Table S1. $\dagger$ These assignments were subsequently confirmed for selected $\mathrm{PGMA}_{28}-\mathrm{PGlyMA}_{n}$ nano-objects using small-angle X-ray scattering (SAXS).

DLS studies indicated the formation of well-defined spheres of with $z$-average diameters $\left(D_{z}\right)$ of $15-26 \mathrm{~nm}$ when targeting short core-forming blocks (e.g. for DP $=25$ at $20 \% \mathrm{w} / \mathrm{w}$ and up to DP $=50$ at $5 \% \mathrm{w} / \mathrm{w}$ ). For copolymer concentrations of $10-30 \% \mathrm{w} / \mathrm{w}$, increasing the core-forming block DP initially afforded a mixed phase of spheres and short worms followed by a pure worm phase, with higher concentrations being required for a lower PGlyMA DP to access the latter morphology. The mean cross-sectional worm core diameter estimated from TEM images was comparable to the mean sphere diameter. For example, $\mathrm{PGMA}_{28}-\mathrm{PGlyMA}_{30}$ spheres prepared at $10 \% \mathrm{w} / \mathrm{w}$ had a mean diameter of $15.6 \pm 1.5 \mathrm{~nm}$, while the cross-sectional diameter for $\mathrm{PGMA}_{28}-\mathrm{PGlyMA}_{50}$ worms was estimated to be $16.6 \pm 1.5 \mathrm{~nm}$ (see Fig. S3†). This is consistent with worm formation via the stochastic 1D fusion of multiple spheres. $^{73}$ Targeting longer PGlyMA DPs produced a mixed phase of worms and vesicles for PISA syntheses conducted at
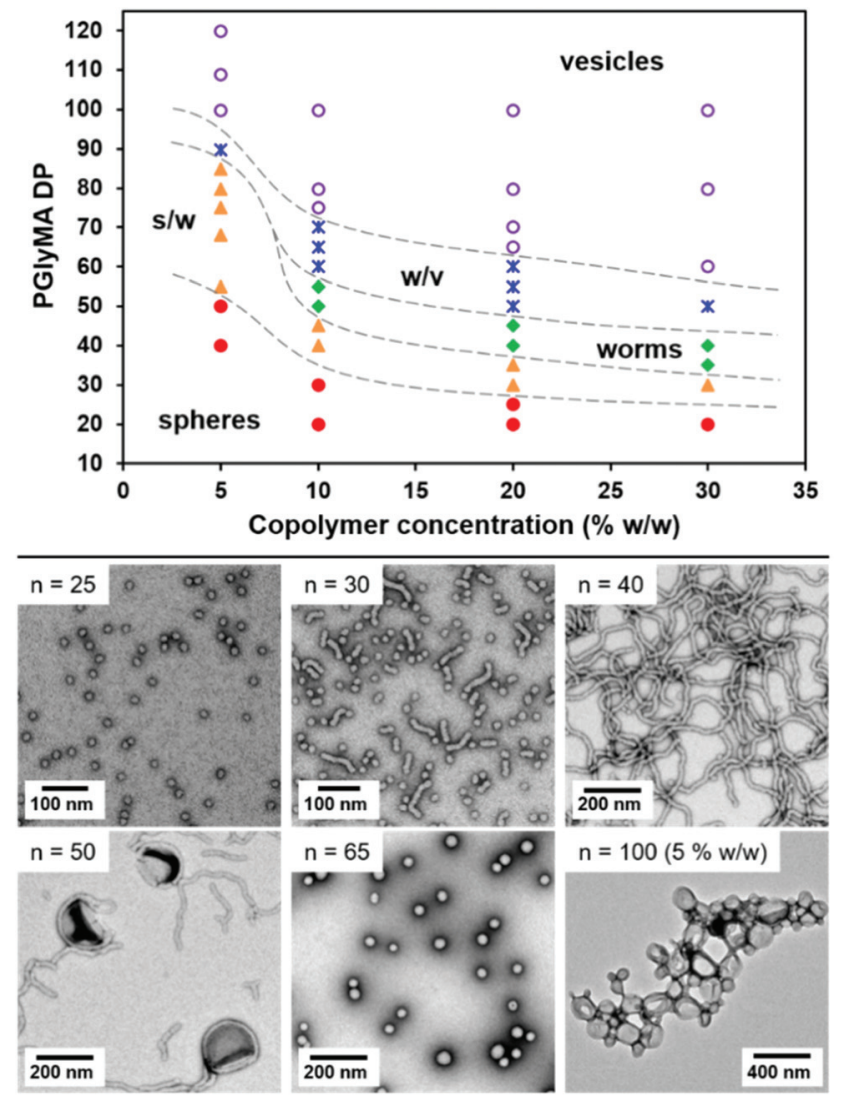

Fig. 1 Phase diagram constructed for a series of $P G M A_{28}-P G l y M A_{n}$ diblock copolymer nano-objects synthesised by RAFT aqueous emulsion polymerisation of GlyMA using a $\mathrm{PGMA}_{28}$ precursor at copolymer concentrations of $10-30 \% \mathrm{w} / \mathrm{w}$ [s/w denotes a mixed phase of spheres and worms, while $\mathrm{w} / \mathrm{v}$ denotes a mixed phase of worms and vesicles]. Representative TEM images are shown for selected nano-objects prepared at $20 \% \mathrm{w} / \mathrm{w}$ (where $n$ indicates the mean PGlyMA DP).

copolymer concentrations of $10-30 \% \mathrm{w} / \mathrm{w}$. Representative TEM images showing the various $\mathrm{PGMA}_{28}-\mathrm{PGlyMA}_{n}$ nano-objects obtained at $10 \% \mathrm{w} / \mathrm{w}$ are shown in Fig. S3. $\dagger$ Based on TEM studies alone, relatively small spheres with $D_{z}$ ranging from 45 to $90 \mathrm{~nm}$ are apparently obtained when targeting PGlyMA DPs of 75-100 at such copolymer concentrations. However, this tentative morphology assignment proved to be erroneous: subsequent SAXS studies confirmed that these 'spheres' were in fact unusually small vesicles (see below for further details). For PISA syntheses performed at $5 \% \mathrm{w} / \mathrm{w}$, larger vesicles were observed when targeting $\mathrm{PGMA}_{28}-\mathrm{PGlyMA}_{100}$ and $\mathrm{PGMA}_{28^{-}}$ PGlyMA $_{110}$, while increasing the PGlyMA DP up to 120 resulted in vesicle aggregates (DLS studies indicated a $D_{z}$ of $1588 \mathrm{~nm}$ and a polydispersity of 0.97 , while visual inspection confirmed that particle sedimentation occurred over time). These experiments clearly demonstrate that the relatively high aqueous solubility of GlyMA monomer $\left(\sim 22 \mathrm{~g} \mathrm{dm}^{-3}\right.$ at $\left.50{ }^{\circ} \mathrm{C}\right)$ provides convenient access to higher order morphologies via RAFT aqueous emulsion polymerisation, thus avoiding the wellknown problem of kinetically-trapped spheres reported in the literature. $^{50-59}$ 


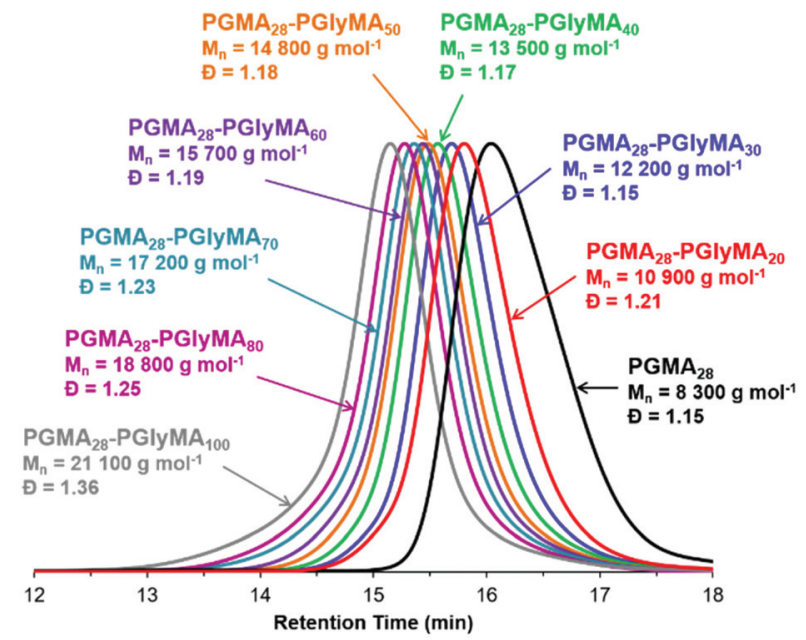

Fig. 2 Overlaid DMF GPC traces recorded for $\mathrm{PGMA}_{28}-\mathrm{PGlyMA}_{n}$ diblock copolymers prepared by RAFT aqueous emulsion polymerisation of GlyMA at $20 \% \mathrm{w} / \mathrm{w}$ solids (conditions: $\mathrm{pH} 7,50^{\circ} \mathrm{C}, 1 \mathrm{~h}$ ) for $n=20,30$, $40,50,60,70,80$ or 100 . Molecular weight data are expressed relative to a series of near-monodisperse poly(methyl methacrylate) calibration standards.

DMF GPC studies of a series of $\mathrm{PGMA}_{28}-\mathrm{PGlyMA}_{n}$ diblock copolymers indicated relatively narrow, unimodal molecular weight distributions, see Fig. 2. These observations are comparable with our previous observations for $\mathrm{PGMA}_{45}-\mathrm{PGlyMA}_{n}$ spheres, where dispersities remained below 1.30 when targeting PGlyMA DPs up to $100 .{ }^{61}$ In the present study, the broader molecular weight distributions observed when targeting higher PGlyMA DPs (Table $\mathrm{S} 1 \dagger$ ) are attributed to low levels of intermolecular branching, which leads to the formation of higher molecular weight species (Fig. 2). Interestingly, in some cases narrower dispersities were obtained when targeting the same diblock copolymer compositions at higher solids. For example, PGMA $_{28}-\mathrm{PGlyMA}_{100}$ prepared at $20 \% \mathrm{w} / \mathrm{w}$ had a dispersity of 1.36 , while the same diblock copolymer prepared at $10 \% \mathrm{w} / \mathrm{w}$ and $5 \% \mathrm{w} / \mathrm{w}$ exhibited dispersities of 1.43 and 1.70 , respectively. It is hypothesised that reaction of a minor fraction of epoxy groups, first with water and then with the hydroxylfunctional monomer that is generated in situ (i.e. glycerol monomethacrylate) generates a small amount of dimethacrylate impurity. ${ }^{63}$ The faster rates of reaction achieved at higher copolymer concentration means that the GlyMA monomer is more quickly converted into less reactive PGlyMA chains, which reduces the propensity for this side-reaction to occur. Moreover, the ensuing intermolecular branching that occurs during GlyMA polymerisation only becomes evident when targeting higher DPs. ${ }^{75}$

\section{Small angle X-ray scattering studies}

In order to confirm the copolymer morphologies assigned by TEM (see Fig. 1), SAXS patterns were recorded for $1.0 \% \mathrm{w} / \mathrm{w}$ aqueous dispersions of three types of $\mathrm{PGMA}_{28}-\mathrm{PGlyMA}_{n}$ nanoobjects originally prepared at $10 \% \mathrm{w} / \mathrm{w}$ solids. Radially-integrated scattering patterns obtained for $\mathrm{PGMA}_{28}-\mathrm{PGlyMA}_{30}$,
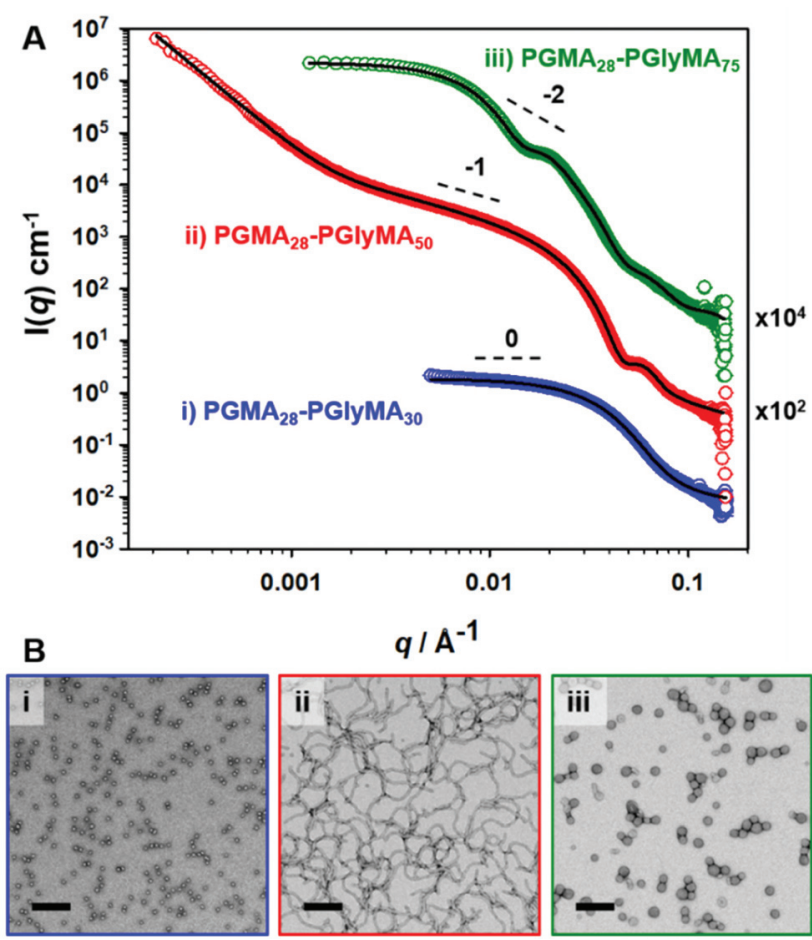

Fig. 3 (A) SAXS patterns recorded for $1.0 \% \mathrm{w} / \mathrm{w}$ aqueous dispersions of $\mathrm{PGMA}_{28}-\mathrm{PGlyMA}_{n}$ nano-objects prepared at $10 \% \mathrm{w} / \mathrm{w}$ solids for (i) $n=$ 30, (ii) $n=50$ and (iii) $n=75$. Experimental data points are denoted by open circles and solid black lines indicate the data fits. For clarity, the red and green curves are offset by arbitrary factors of $10^{2}$ and $10^{4}$, respectively. (B) Representative TEM images recorded for the corresponding (i) $P G M A_{28}-P G l y M A_{30}$, (ii) $P G M A_{28}-P G l y M A_{50}$ and (iii) $\mathrm{PGMA}_{28}-$ $\mathrm{PGlyMA}_{75}$ nano-objects. Scale bars represent $200 \mathrm{~nm}$ in each case.

PGMA $_{28}-$ PGlyMA $_{50}$ and PGMA $28-$ PGlyMA $_{75}$ are shown in Fig. 3, where $q$ is the scattering vector and $I(q)$ is the X-ray scattering intensity. These scattering patterns were fitted using a PGlyMA homopolymer density of $1.25 \pm 0.01 \mathrm{~g} \mathrm{~cm}^{-3}$ as determined by helium pycnometry. The PGlyMA scattering length density $\left(\xi_{\text {PGlyMA }}=11.34 \times 10^{10} \mathrm{~cm}^{-2}\right)$ is comparable to that of the PGMA stabiliser block $\left(\xi_{\text {PGMA }}=11.94 \times 10^{10} \mathrm{~cm}^{-2} ; \xi_{\text {water }}=9.42\right.$ $\times 10^{10} \mathrm{~cm}^{-2}$ ) so the scattering from each component is comparable. To minimise the number of adjustable parameters when fitting these scattering patterns, the solvent volume fraction within the PGlyMA cores $\left(x_{\text {sol }}\right)$ was taken to be zero. This assumption is reasonable given the relatively hydrophobic nature of these chains. Moreover, when $x_{\text {sol }}$ was allowed to vary during preliminary attempts to model the data, this parameter always tended to zero. A detailed description of the scattering models and fitting parameters utilised to analyse these SAXS patterns is provided in the ESI (see SAXS section and Table S2 $\dagger$ ).

The SAXS pattern obtained for $\mathrm{PGMA}_{28}-\mathrm{PGlyMA}_{30}$ could be satisfactorily fitted using a spherical micelle model. ${ }^{76}$ A low $q$ gradient of approximately zero was obtained, which is consistent with the spherical morphology indicated by TEM studies, see Fig. 3B(i). The volume-average sphere diameter, $D_{\mathrm{s}}$, calculated from this model was $15.5 \mathrm{~nm}$. As expected, this is lower 
than the $z$-average sphere diameter, $D_{z}$, of $21 \mathrm{~nm}$ reported by DLS. The SAXS pattern recorded for $\mathrm{PGMA}_{28}-\mathrm{PGlyMA}_{50}$ had a gradient of approximately -1 at low $q$, which indicates a highly anisotropic morphology. ${ }^{77}$ Again, this is consistent with the corresponding TEM image, which reveals a pure worm phase. The upturn at low $q$ (below $q \sim 0.02 \AA^{-1}$ ) suggests either some degree of worm branching (for which there appears to be some TEM evidence) or inter-worm interactions. The volume-average cross-sectional worm diameter, $D_{\mathrm{w}}$, was calculated to be $17.8 \pm 1.7 \mathrm{~nm}$ by fitting the SAXS pattern to a worm-like micelle model. ${ }^{76}$ This is in good agreement with the number-average worm width estimated by TEM $(16.6 \pm 1.5 \mathrm{~nm})$. Perusal of the PISA literature indicates that well-defined worms are seldom reported for RAFT aqueous emulsion polymerisation formulations, which tend to produce kinetically-trapped spheres. Even in the few cases where anisotropic worms (sometimes described as nanofibres) are reported, close inspection of TEM images usually indicates the presence of minor populations of either spheres or vesicles. ${ }^{40,44}$ Although the PGMA $_{28}$-PGlyMA $_{75}$ nanoparticles were initially assigned as spheres by TEM, a spherical micelle model could not be fitted to the scattering pattern recorded for this dispersion (see Fig. S4†). However, satisfactory data fits could be obtained when using a vesicle model. ${ }^{78}$ Moreover, the volume-average vesicle diameter $\left(D_{\mathrm{v}}\right)$ of $53 \mathrm{~nm}$ calculated using this latter model was consistent with the corresponding DLS diameter, $D_{z}$, of $64 \mathrm{~nm}$ (see Table S2 $\dagger$ ). The mean vesicle membrane thickness, $T_{\mathrm{m}}$, was calculated to be $8.2 \mathrm{~nm}$, which is relatively large relative to the vesicle diameter. Thus, these rather small vesicles are much more resistant to deformation under ultrahigh vacuum than the larger vesicles commonly reported in the PISA literature, ${ }^{26}$ which makes their unambiguous morphological assignment using TEM alone somewhat problematic. This example serves to highlight the importance of using a statistically robust scattering technique such as SAXS for structural characterisation, rather than simply relying on TEM observations. SAXS patterns recorded for other $\mathrm{PGMA}_{28}-\mathrm{PGlyMA}_{n}$ nanoparticles (where $n=20,55,80$ or 100 ) prepared at $10 \% \mathrm{w} / \mathrm{w}$ can be found in Table S2† and Fig. S5 (see ESI $\dagger$ ).

\section{Long-term stability of epoxy groups for aqueous dispersions of} PGMA $_{28}$-PGlyMA 5 worms

The chemical stability of PGMA $_{28}-$ PGlyMA $_{55}$ worms was assessed during the long-term storage of a $10 \% \mathrm{w} / \mathrm{w}$ aqueous dispersion for 12 weeks at $20{ }^{\circ} \mathrm{C}$. It is well-known that epoxy groups are susceptible to nucleophilic ring-opening by water, or by neighbouring hydroxyl groups. ${ }^{63}$ Nevertheless, ${ }^{1} \mathrm{H}$ NMR spectroscopy studies indicated that $90 \%$ of the original epoxy groups remained intact after 6 weeks at $\mathrm{pH} 7$, although only $74 \%$ were retained after ageing for 12 weeks (Fig. 4A). These observations are in good agreement with the gradual loss of epoxy functionality previously reported for $\mathrm{PGMA}_{45}{ }^{-}$ PGlyMA $_{100}$ spheres. $^{64}$ Moreover, a concomitant increase in dispersity was observed when analyzing the aged $\mathrm{PGMA}_{28^{-}}$ PGlyMA $_{55}$ chains by DMF GPC (Fig. 4B). This suggests that
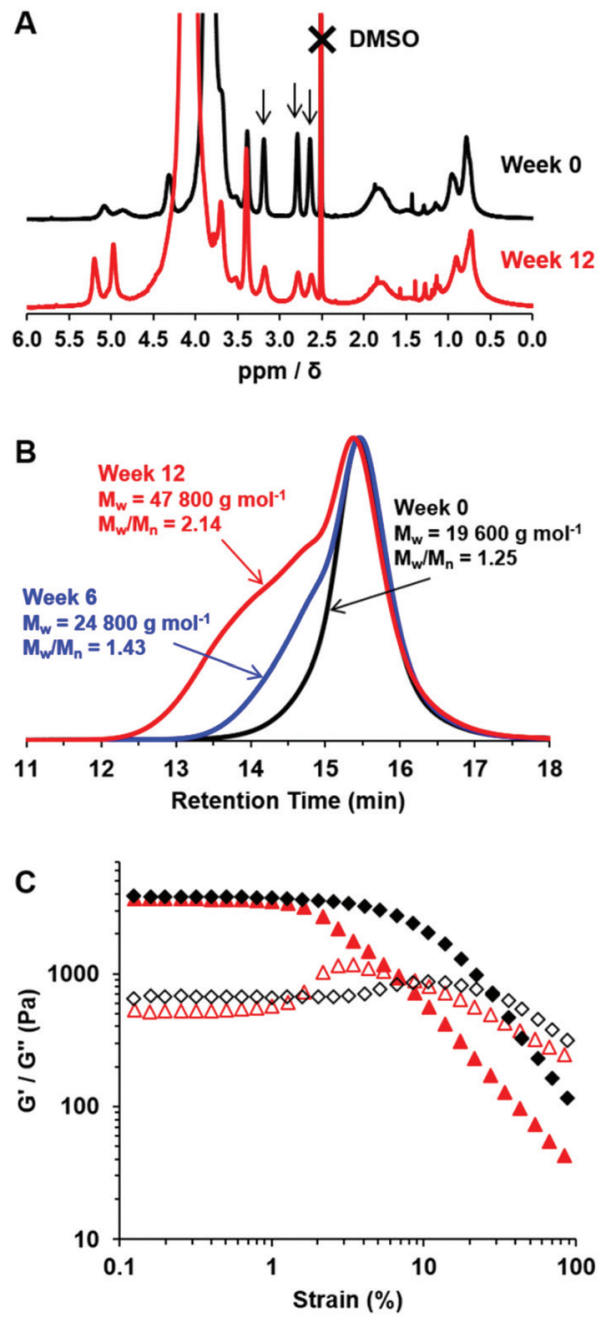

Fig. 4 Evaluation of the chemical stability of the epoxy groups within a $10 \% \mathrm{w} / \mathrm{w}$ aqueous dispersion of $\mathrm{PGMA}_{28}-\mathrm{PGlyMA}_{55}$ worms during their long-term storage at $20^{\circ} \mathrm{C}$ and $\mathrm{pH}$ 7. (A) ${ }^{1} \mathrm{H}$ NMR spectra confirm that ring-opening of epoxy groups occurs gradually over time as a result of nucleophilic attack by water. (B) DMF GPC traces recorded for the molecularly-dissolved diblock copolymer chains at various time points, indicating light branching caused by intermolecular ring-opening side reactions. (C) Rheological strain sweeps showing $G^{\prime}$ (closed symbols) and $G^{\prime \prime}$ (open symbols) for fresh $\mathrm{PGMA}_{28}-\mathrm{PGlyMA}_{55}$ worms (black diamonds) and the same worms after ageing for 12 weeks (red triangles). The yield strain of this worm gel is reduced significantly after long-term storage at $20^{\circ} \mathrm{C}$.

the hydroxyl groups that are generated via ring-opening of the epoxy groups by reaction with water subsequently react with adjacent epoxy groups, leading to intermolecular branching. Given the relatively low degree of hydration of such diblock copolymer nano-objects indicated by SAXS studies, this chemical degradation presumably involves initial reaction of epoxy groups located at the near-surface of the PGlyMA cores. Interestingly, rheological studies of the $10 \%$ w/w worm gel revealed a significant reduction in the critical strain $\left(\gamma_{c}\right)$ from $10 \%$ to $2.4 \%$, suggesting that gel embrittlement occurs over time (Fig. 4C). 
Derivatisation of PGMA $_{28}$-PGlyMA $n$ spheres, worms and vesicles using L-cysteine

The inherent reactivity of the epoxy ring offers a convenient handle for post-polymerisation derivatisation of freshly-prepared PGMA-PGlyMA nano-objects. We, and other labs, have previously demonstrated that either homopolymerisation or statistical copolymerisation of GlyMA to form core-forming blocks ${ }^{64}$ enables the facile preparation of covalently-stabilised nanoparticles using various diamines, ${ }^{65,79,80}$ 3-aminopropyltriethoxysilane ${ }^{66,81}$ or 3-mercaptopropyltrimethoxysilane as crosslinkers. ${ }^{82}$ Moreover, we recently reported the use of epoxyfunctional stabiliser blocks to functionalise spherical nanoparticles via epoxy-thiol chemistry ${ }^{83}$ and also block copolymer worms via epoxy-amine chemistry. ${ }^{48,64}$ Here, we examine epoxy-thiol chemistry for the convenient derivatisation of PGMA $_{28}-$ PGlyMA $_{25}$ spheres, PGMA $_{28}-$ PGlyMA $_{40}$ worms and $\mathrm{PGMA}_{28}-\mathrm{PGlyMA}_{80}$ vesicles with $\mathrm{L}$-cysteine at $\mathrm{pH} 8.5$ to afford the corresponding PGMA $_{28}-\mathrm{P}(\text { GlyMA-Cys })_{n}$ nano-objects directly in water, see Scheme 2.

An as-prepared $20 \% \mathrm{w} / \mathrm{w}$ aqueous dispersion of each type of PGMA $_{28}$-PGlyMA $n$ diblock copolymer nano-object was diluted to $5 \% \mathrm{w} / \mathrm{w}$ (primarily to allow efficient stirring in the case of the PGMA $_{28}-$ PGlyMA $_{40}$ diblock copolymer worms). Excess L-cysteine (L-cysteine/epoxy molar ratio $=10$ ) was added and allowed to react with the epoxy groups at $\mathrm{pH} 8.5$, which is close to the $\mathrm{p} K_{\mathrm{a}}$ of its thiol group $\left(\mathrm{p} K_{\mathrm{a}} \approx 8.2\right)$. Therefore, this amino acid reagent is present in its more reactive thiolate form, while its primary amine group remains protonated $\left(\mathrm{p} K_{\mathrm{a}}\right.$ $\approx 10.3$ ) to minimise epoxy-amine side-reactions. Following epoxy-thiol derivatisation for $24 \mathrm{~h}$ at $20{ }^{\circ} \mathrm{C}$, the unreacted L-cysteine was removed by dialysis and the purified copolymer spheres, worms and vesicles were freeze-dried prior to elemental microanalyses (see Table S3†). Both the nitrogen and sulfur contents of these nano-objects increased significantly after L-cysteine derivatisation, from $0.23 \%$ and $1.04 \%$ in the original $\mathrm{PGMA}_{28}-\mathrm{PGlyMA}_{25}$ spheres up to $2.94 \%$ and $6.98 \%$, respectively for $\mathrm{PGMA}_{28} \mathrm{P}(\text { GlyMA-cys })_{25}$. The latter values indicate a mean degree of derivatisation of $91 \%$. Similarly, the nitrogen and sulfur contents increased from $0.16 \%$ and $0.70 \%$ for the original $\mathrm{PGMA}_{28}-\mathrm{PGlyMA}_{40}$ worms up to $3.42 \%$ and $8.02 \%$ for
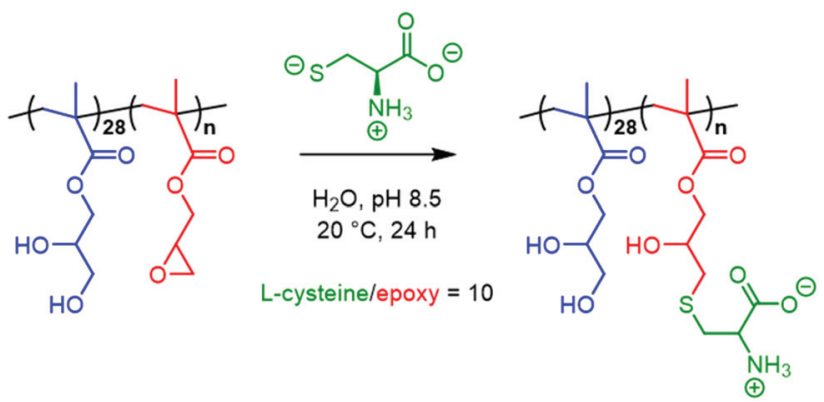

Scheme 2 Schematic representation of the derivatisation of a $5 \% \mathrm{w} / \mathrm{w}$ aqueous dispersion of $\mathrm{PGMA}_{28}-\mathrm{PGlyMA}_{n}$ nano-objects via epoxy-thiol chemistry using excess L-cysteine (conditions: L-cysteine/epoxy molar ratio $=10 ; \mathrm{pH} 8.5 ; 20^{\circ} \mathrm{C}, 24 \mathrm{~h}$ ). the PGMA $_{28}-\mathrm{P}$ (GlyMA-cys) ${ }_{40}$ worms, which is equivalent to a mean degree of derivatisation of $91 \%$. In contrast, a much lower mean degree of derivatisation of $44.5 \%$ was obtained for the $\mathrm{PGMA}_{28} \mathrm{P}$ (GlyMA-cys) $)_{80}$ vesicles. Accordingly, a ten-fold excess of $\mathrm{L}$-cysteine was added to a $5 \% \mathrm{w} / \mathrm{w}$ aqueous dispersion of PGMA $_{28}-$ PGlyMA $_{80}$ vesicles and this reaction mixture was heated to $50{ }^{\circ} \mathrm{C}$ for $24 \mathrm{~h}$. After exhaustive dialysis and freezedrying, the mean degree of derivatisation indicated by elemental microanalysis was much higher (89\%).

The PGMA $_{28}-\mathrm{P}(\text { GlyMA-cys })_{n}$ copolymer nano-objects were characterised by TEM and DLS studies (see Fig. 5 and Table $\mathrm{S} 4, \dagger$ respectively). The former technique confirmed that the worm (Fig. 5E) and vesicle (Fig. 5F) morphologies were retained after $\mathrm{L}$-cysteine derivatisation. However, the welldefined PGMA $_{28}-$ PGlyMA $_{25}$ spheres (Fig. 5A; $D_{z}=18 \mathrm{~nm}$, DLS polydispersity $=0.12$ ) did not retain their original spherical morphology after derivatisation (Fig. 5D). DLS studies indicated that, although the $D_{z}$ value was comparable $(14 \mathrm{~nm})$, the
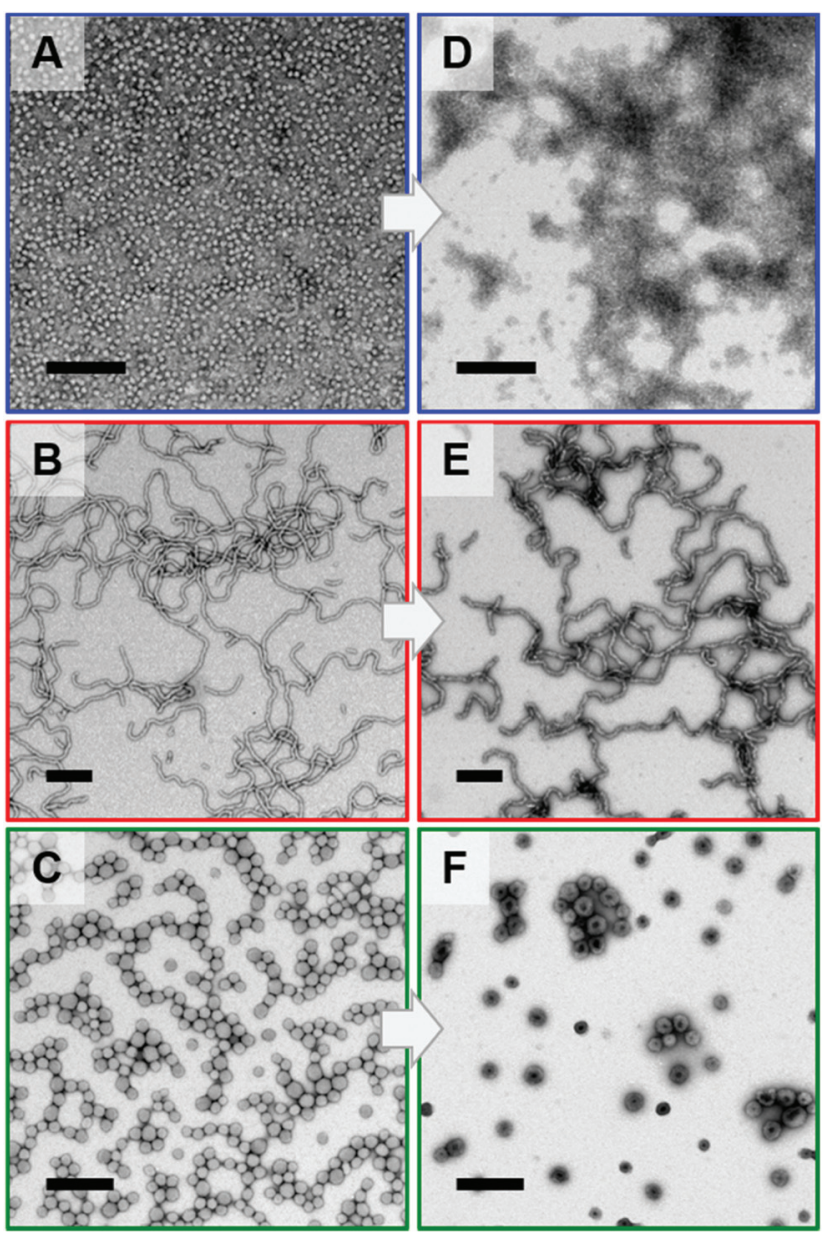

Fig. 5 TEM images recorded for (A) $P G M A_{28}-P_{G l y M A_{25}}$ spheres, (B) $\mathrm{PGMA}_{28}-\mathrm{PGlyMA}_{40}$ worms and (C) $\mathrm{PGMA}_{28}-\mathrm{PGlyMA}_{80}$ vesicles, (D) molecularly-dissolved $\mathrm{PGMA}_{28}-\mathrm{P}$ (GlyMA-cys) ${ }_{25}$ chains (derivatised using excess L-cysteine at $20^{\circ} \mathrm{C}$ ), (E) PGMA 28 -P(GlyMA-cys) 40 worms (derivatised using excess L-cysteine at $20^{\circ} \mathrm{C}$ ) and (F) PGMA 28 -P(GlyMA-cys) ${ }_{80}$ vesicles (derivatised using excess L-cysteine at $50^{\circ} \mathrm{C}$ ). Scale bars represent $200 \mathrm{~nm}$ in each case. 
corresponding polydispersity had increased to 0.36 with a concomitant reduction in the scattered light intensity (count rate). This suggested that the originally hydrophobic PGlyMA chains had become sufficiently hydrophilic after derivatisation to cause partial molecular dissolution of the original spheres. This interpretation was confirmed by SAXS analysis of $1.0 \%$ $\mathrm{w} / \mathrm{w}$ aqueous dispersions of the same spheres, worms and vesicles before and after derivatisation using L-cysteine, see Fig. 6.

SAXS patterns recorded for the as-synthesised $\mathrm{PGMA}_{28^{-}}$ PGlyMA $_{25}$ spheres, PGMA $_{28}-$ PGlyMA $_{40}$ worms and PGMA $_{28}{ }^{-}$ PGlyMA $_{80}$ vesicles (Fig. 6A) were fitted using a spherical micelle model, ${ }^{76}$ a worm-like micelle model $^{76}$ or a vesicle model, ${ }^{78}$ respectively, as previously described (see Table S5 $\dagger$ for a summary of the fitting parameters). SAXS patterns were also recorded following derivatisation of these nano-objects with L-cysteine in aqueous solution (Fig. 6B). The scattering pattern obtained for $\mathrm{PGMA}_{28}-\mathrm{P}(\text { GlyMA-cys })_{25}$ was consistent with that expected for molecularly-dissolved copolymer chains and could be fitted using a Gaussian coil model. ${ }^{84}$ However, despite the relatively low copolymer concentration of $1.0 \%$ $\mathrm{w} / \mathrm{w}$, a satisfactory data fit could only be achieved by incorporating an appropriate structure factor to account for the polyelectrolytic nature of the derivatised copolymer chains. More specifically, the Hayter-Penfold approximation for coulombic interactions ${ }^{85}$ was used to account for charge repulsion, with the particle charge being estimated from initial fittings. Owing to the zwitterionic nature of the cysteine-derivatised copolymers, the formal overall charge was not expected to deviate significantly from neutrality. Electrophoretic mobility studies performed under the same conditions as those studied by SAXS indicated a negative zeta potential at $\mathrm{pH} 7$ (see Table $\mathrm{S} 4 \dagger$ ), which is consistent with the expected contribution from anionic carboxylate groups.
A satisfactory fit to the SAXS pattern recorded for the $\mathrm{PGMA}_{28}-\mathrm{P}(\text { Gly-cys })_{40}$ worms was obtained using a worm-like micelle model $^{76}$ provided that a minor population of molecularly-dissolved copolymer chains was included (fitted to a generalised Gaussian coil model using the Hayter-Penfold approximation, ${ }^{85}$ as previous described). Interestingly, SAXS analysis indicated that the mean cross-sectional diameter of the worm cores, $D_{\mathrm{w}}$, increased from $15.3 \mathrm{~nm}$ to $17.8 \mathrm{~nm}$ after L-cysteine derivatisation. TEM analyses of the dried copolymer worms confirmed this change in dimensions: $D_{\mathrm{w}}$ increased from $13 \mathrm{~nm}$ for the precursor worms to $16 \mathrm{~nm}$ after derivatisation. Similarly, the SAXS pattern recorded for the $\mathrm{PGMA}_{28}-\mathrm{P}$ (Gly-cys $_{80}$ vesicles was fitted using a vesicle model $^{78}$ by incorporating the Hayter-Penfold approximation. ${ }^{85}$ However, an additional population was required to account for the presence of a small number of large scattering objects, which suggests incipient aggregation. The volume-average diameter, $D_{\mathrm{v}}$, increased from $45 \mathrm{~nm}$ for the precursor vesicles to $58 \mathrm{~nm}$ after derivatisation, with a corresponding increase in the vesicle membrane thickness, $T_{\mathrm{m}}$, from 7.5 to $9.7 \mathrm{~nm}$. DLS studies indicated that the $\mathrm{PGMA}_{28}-\mathrm{PGlyMA}_{80}$ precursor vesicles exhibited a $z$-average diameter, $D_{z}$, of $49 \mathrm{~nm}$, whereas that for the final $\mathrm{PGMA}_{28} \mathrm{P}(\mathrm{Gly} \text {-cys })_{80}$ vesicles was $81 \mathrm{~nm}$. Interestingly, the vesicular morphology was much more clearly visualised by TEM after epoxy-thiol derivatisation, which suggests a stronger interaction of the ionic groups with the TEM staining agent (uranyl formate).

In summary, L-cysteine derivatisation introduces a significant amount of charge into the originally hydrophobic PGlyMA chains. This accounts for the sphere-to-unimer transition observed for $\mathrm{PGMA}_{28}-\mathrm{PGlyMA}_{25}$ spheres and also the increase in size for the $\mathrm{PGMA}_{28}-\mathrm{PGlyMA}_{40}$ worms and the PGMA $_{28}-$ PGlyMA $_{80}$ vesicles.
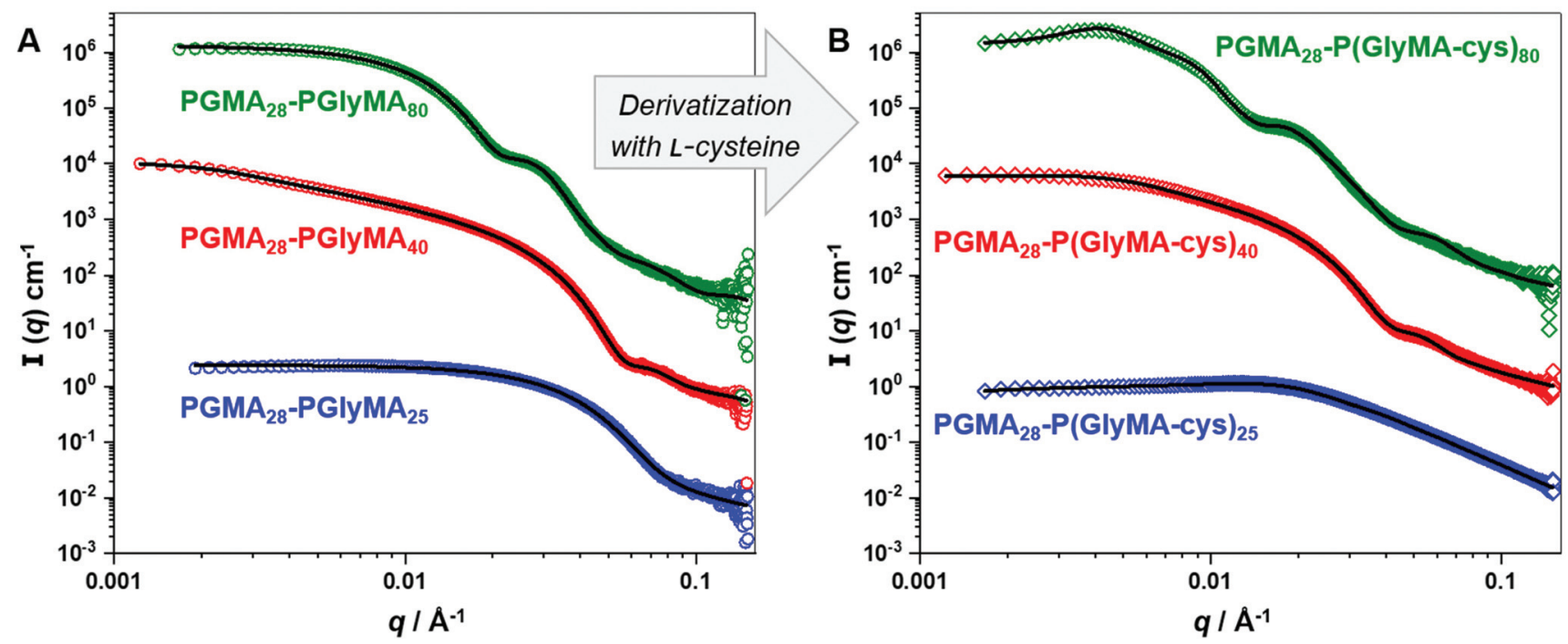

Fig. 6 SAXS patterns recorded for $1.0 \% \mathrm{w} / \mathrm{w}$ aqueous dispersions of (A) precursor $\mathrm{PGMA}_{28}-\mathrm{PGlyMA}_{25}$ spheres, $\mathrm{PGMA} \mathrm{A}_{28}-\mathrm{PGlyMA} 40$ worms and $\mathrm{PGMA}_{28}-\mathrm{PGlyMA}_{80}$ vesicles originally prepared at $20 \% \mathrm{w} / \mathrm{w}$ solids, and (B) the corresponding molecularly-dissolved $\mathrm{PGMA} \mathrm{A}_{28}-\mathrm{P}(\mathrm{GlyMA}-\mathrm{cys})_{25}$ chains,

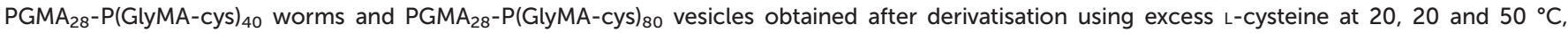
respectively. Experimental data points are denoted by open symbols and solid black lines indicate data fits. 
In situ SAXS studies during RAFT aqueous emulsion polymerisation of GlyMA

We recently reported the first in situ SAXS studies during RAFT aqueous emulsion polymerisation of MOEMA at $10 \% \mathrm{w} / \mathrm{w}$ solids using a bespoke stirrable reaction cell. ${ }^{47}$ Here, we use the same experimental set-up to monitor the RAFT aqueous emulsion polymerisation of GlyMA and hence examine the nucleation and growth of $\mathrm{PGMA}_{48}-\mathrm{PGlyMA}_{100}$ spheres at $10 \%$ $\mathrm{w} / \mathrm{w}$ solids. Such spheres were targeted for this in situ SAXS experiment because they were larger $\left(D_{z}=37 \mathrm{~nm}\right)$ than the spheres prepared using the PGMA 28 precursor $\left(D_{z}=15-21 \mathrm{~nm}\right.$; Table $\mathrm{S} \dagger)$. Larger spheres are easier to image by postmortem TEM analysis, which was conducted to compare the $\mathrm{PGMA}_{48^{-}}$ PGlyMA $_{100}$ spheres formed during this in situ SAXS experiment with the equivalent laboratory-scale formulation performed in the absence of any synchrotron radiation. ${ }^{1} \mathrm{H}$ NMR spectroscopy studies confirmed that a high monomer conversion was achieved in both cases (>98\% within $1 \mathrm{~h}$ at $\left.50{ }^{\circ} \mathrm{C}\right)$. DMF GPC analysis indicated that the molecular weight distributions for the two diblock copolymers were comparable $\left(M_{\mathrm{n}}=22800\right.$; $M_{\mathrm{w}} / M_{\mathrm{n}}=1.18 v$ s. $M_{\mathrm{n}}=26800 ; M_{\mathrm{w}} / M_{\mathrm{n}}=1.22$ for the in situ SAXS and laboratory-scale syntheses, respectively), see Fig. S6A. $\dagger$ DLS measurements indicated that relatively narrow unimodal size distributions were obtained in both cases (Fig. $\mathrm{S} 6 \mathrm{~B} \dagger$ ). However, a $D_{z}$ of $26 \mathrm{~nm}$ was observed for the nanoparticles prepared during the in situ SAXS experiment, which is somewhat lower than that for the nanoparticles $\left(D_{z}=37 \mathrm{~nm}\right)$ obtained from the laboratory-scale synthesis. Postmortem TEM images indicated the formation of well-defined spheres for both PISA formulations, see Fig. 7.

SAXS patterns were collected every $2.5 \mathrm{~min}$ for $40 \mathrm{~min}$, see Fig. 8A. As recently reported for the RAFT aqueous emulsion polymerisation of MOEMA, we focus on two key aspects of this PISA formulation: (i) the timescale for the onset of micellar nucleation and (ii) the timescale for cessation of the polymerisation. During the laboratory-scale experiment (Fig. 8B), the initial rate of polymerisation was relatively slow and the onset of nucleation was observed after $22 \mathrm{~min}$; the instan-

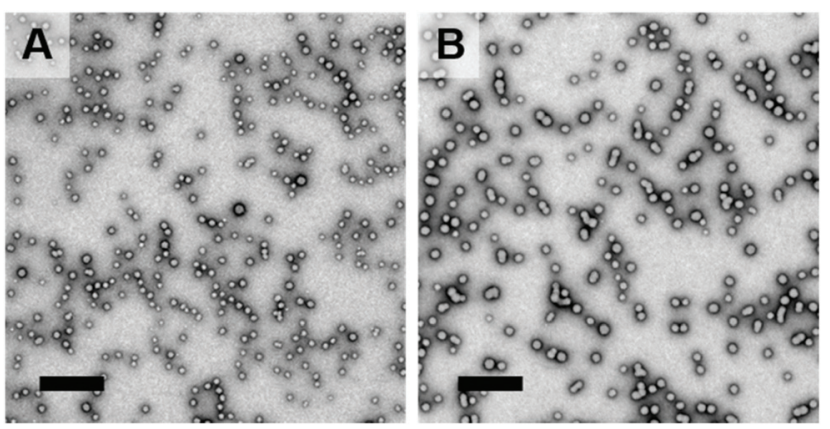

Fig. 7 Representative TEM images recorded for the dried $\mathrm{PGMA}_{48}$ PGlyMA 100 spheres prepared via RAFT aqueous emulsion polymerisation of GlyMA at $10 \% \mathrm{w} / \mathrm{w}$ solids at $50{ }^{\circ} \mathrm{C}$ : (a) after in situ SAXS experiments (b) after the equivalent laboratory-scale synthesis conducted in the absence of X-ray synchrotron radiation using the same PISA formulation. Scale bars represent $200 \mathrm{~nm}$.
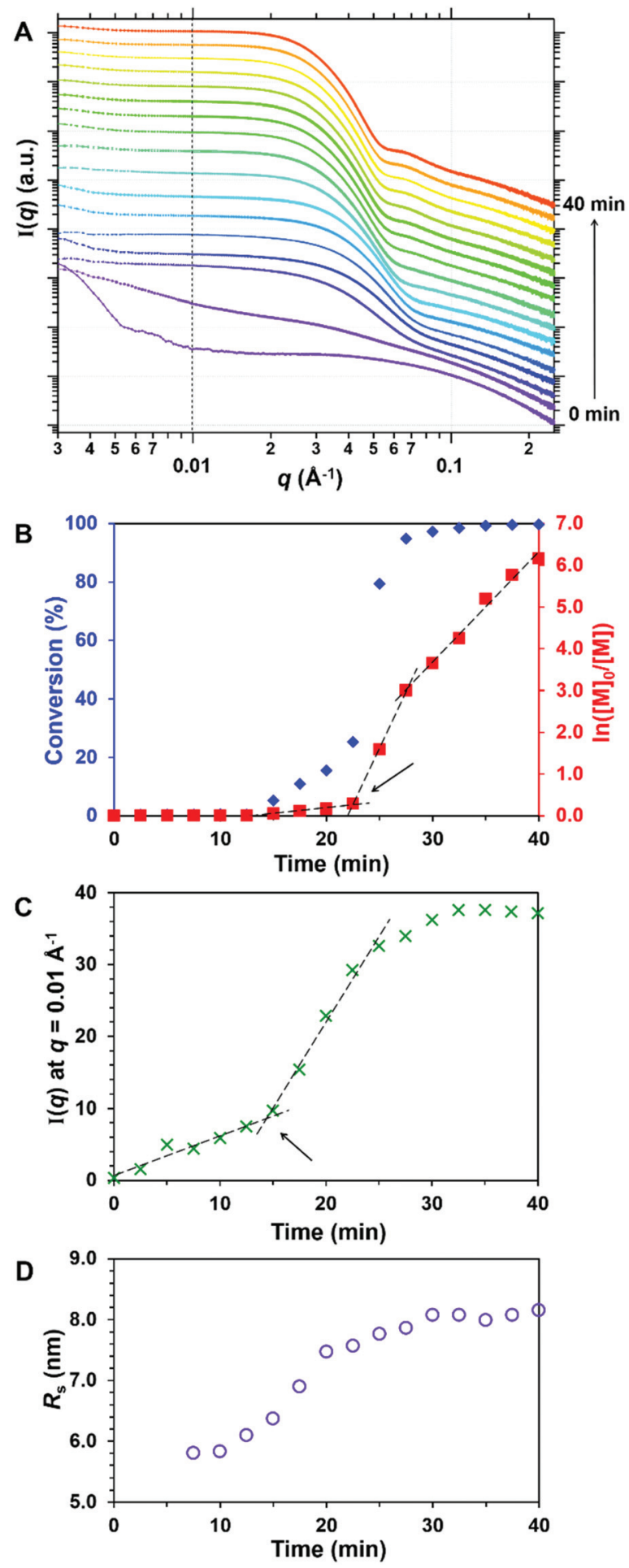

Fig. 8 SAXS patterns recorded during the RAFT aqueous emulsion polymerisation of GlyMA targeting $\mathrm{PGMA}_{48}-\mathrm{PGlyMA}_{100}$ spheres at $10 \%$ $\mathrm{w} / \mathrm{w}$ solids using a stirrable reaction cell. (A) SAXS patterns recorded every $2.5 \mathrm{~min}$ from 0 to $40 \mathrm{~min}$. (B) Conversion vs. time curve and corresponding semi-logarithmic plot obtained for the equivalent laboratory-scale synthesis. (C) the $I(q)$ at $q=0.01 \AA^{-1}$ as a function of time. (D) Evolution of the mean sphere core radius, $R_{\mathrm{S}}$, over time, calculated using $R_{\mathrm{s}}=4.49 / q$, where $q$ is the local minimum between $0.078-0.054 \AA^{-1}$. Arrows indicate the onset of micellar nucleation. 
taneous conversion was $25 \%$, which corresponded to a critical PGlyMA DP of 25. This GlyMA polymerisation was essentially complete ( $>98 \%$ conversion) within $35 \mathrm{~min}$ at $50{ }^{\circ} \mathrm{C}$. To assess the onset of micellar nucleation during the in situ SAXS experiment, the scattering intensity, $I(q)$, at an arbitrary $q$ of $0.01 \AA^{-1}$ was plotted as a function of time, see Fig. 8C. An upturn was observed at 14 min owing to the formation of larger scattering objects, thus indicating the onset of micellar nucleation. No further change in the scattering patterns was discernible after 33 min, so the GlyMA polymerisation was judged to be complete on this timescale. Thus, both the onset of nucleation and cessation of the polymerisation occurred within slightly shorter timescales for the in situ SAXS experiment. This is attributed to a modest rate enhancement caused by the ionising nature of the high-energy X-rays which generates an additional radical flux; ${ }^{86,87}$ such observations are consistent with our prior in situ SAXS studies of other PISA formulations. ${ }^{47,88}$ The mean sphere core radius, $R_{\mathrm{s}}$, can be estimated from the local minimum at $q=0.075 \AA^{-1}$ that becomes discernible after nucleation, using the well-known relationship $d=4.49 / q$, where $d$ is a real-space distance corresponding to $R_{\mathrm{s}}$ (the mean core radius in $\AA$ ). This local minimum gradually shifts to lower $q$ throughout the polymerisation, see Fig. 8D. More specifically, $R_{\mathrm{S}}$ increases from 5.80 to $8.16 \mathrm{~nm}$, indicating a final volume-average spherical core diameter of $16.3 \mathrm{~nm}$. The final PGMA $_{48}-$ PGlyMA $_{100}$ diblock copolymer nanoparticles obtained after the in situ SAXS experiment were diluted to $1.0 \% \mathrm{w} / \mathrm{w}$ and a SAXS pattern was recorded. The data were fitted to a spherical micelle model, ${ }^{76}$ see Fig. $S 7, \dagger$ to give a volume-average overall sphere diameter, $D_{\mathrm{S}}$, of $23.1 \mathrm{~nm}$, where $D_{\mathrm{s}}=2 R_{\mathrm{S}}+4 R_{\mathrm{g}}$. Given that DLS is known to be more biased towards larger particles than SAXS, this is consistent with the corresponding $D_{z}$ diameter of $26 \mathrm{~nm}$. Parameters such as the mean sphere core radius $\left(R_{\mathrm{S}}\right)$ and mean radius of gyration of the $\mathrm{PGMA}_{48}$ stabiliser block $\left(R_{\mathrm{g}}\right)$ calculated from fitting this SAXS pattern enabled the $10 \% \mathrm{w} / \mathrm{w}$ final SAXS pattern recorded after 40 min to be analysed using a spherical micelle model by incorporating an appropriate structure factor to account for the higher nanoparticle concentration (Fig. S8†). This latter analysis afforded a comparable $D_{\mathrm{s}}$ of $23.3 \mathrm{~nm}$. Fitting parameters and further information regarding these SAXS models can be found in the ESI and are summarised in Table S6. $\dagger$

\section{Conclusions}

Using a sufficiently short non-ionic PGMA $_{28}$ stabiliser block for the RAFT aqueous emulsion polymerisation of GlyMA under mild conditions $\left(50{ }^{\circ} \mathrm{C}, \mathrm{pH} 7\right.$ ) provides convenient access to epoxy-functional spheres, worms and vesicles. This is attributed to the relatively high aqueous solubility of GlyMA $\left(\sim 22 \mathrm{~g} \mathrm{dm}^{-3}\right)$, which enables the restrictive paradigm of kinetically-trapped spheres observed for many such PISA formulations to be circumvented. High GlyMA conversions (>98\%) can be obtained within $1 \mathrm{~h}$ and molecular weight distributions remained relatively narrow $\left(M_{\mathrm{w}} / M_{\mathrm{n}}<1.5\right)$ if the target PGlyMA
DP remains below 100. A pseudo-phase diagram was constructed for the synthesis of $\mathrm{PGMA}_{28}-\mathrm{PGlyMA}_{n}$ nano-objects at copolymer concentrations ranging from 5 to $30 \% \mathrm{w} / \mathrm{w}$. This systematic approach is essential for the reproducible targeting of pure spheres, worms or vesicles. Each morphology was initially assigned on the basis of TEM studies and subsequently confirmed by SAXS analysis. However, long-term storage of a $10 \% \mathrm{w} / \mathrm{w}$ aqueous dispersion of $\mathrm{PGMA}_{28}-\mathrm{PGlyMA}_{55}$ worms under ambient conditions led to a $26 \%$ loss of the original epoxy groups over 12 weeks, as determined by ${ }^{1} \mathrm{H}$ NMR spectroscopy. Concomitant GPC studies indicated that significant broadening of the molecular weight distribution occurred over the same time period. This suggests that the hydroxyl groups generated via ring-opening of the epoxy groups by reaction with water can themselves react with adjacent epoxy groups, leading to intermolecular branching. The epoxy-functional cores of aqueous dispersions of $\mathrm{PGMA}_{28}-\mathrm{PGlyMA}_{n}$ diblock copolymer spheres, worms and vesicles can be conveniently derivatised by reacting with excess L-cysteine to afford zwitterionic copolymers. Elemental microanalyses indicate that high degrees of derivatisation (89-91\%) can be achieved using such this epoxy-thiol chemistry. Finally, an in situ SAXS study was conducted during the RAFT aqueous emulsion polymerisation of GlyMA, targeting $\mathrm{PGMA}_{48}{ }^{-}$ PGlyMA $_{100}$ spheres. A modest rate enhancement was observed for this experiment, with both nucleation and cessation of the polymerisation occurring on somewhat shorter timescales compared to the equivalent laboratory-scale formulation owing to the ionising nature of the high-energy X-ray synchrotron beam. Postmortem TEM and DLS analysis confirmed that welldefined spheres were obtained in both cases and the evolution of the sphere core diameter over the time was monitored.

\section{Conflicts of interest}

There are no conflicts of interest to declare.

\section{Acknowledgements}

S. P. A. thanks the ERC for an Advanced Investigator grant (PISA 320372) to support F. L. H. and the EPSRC for an Established Career Fellowship in Particle Technology (EP/ R003009). The Leverhulme Trust is also thanked for post-doctoral funding of M. J. D. (RPG-2016-330). The authors wish to thank the European Synchrotron Radiation Facility and Diamond Light Source for providing synchrotron beamtime at ID02 station (beamtime proposal numbers SC4384 and SC4864) and I22 station (beamtime proposal number SM15933), respectively. Dr Svetomir Tzokov is thanked for carbon-coating the TEM grids.

\section{References}

1 G. Riess, Prog. Polym. Sci., 2003, 28, 1107-1170. 
2 L. Zhang and A. Eisenberg, Science, 1995, 268, 1728-1731.

3 Y. Y. Won, H. T. Davis and F. S. Bates, Science, 1999, 283, 960-963.

4 W.-N. He and J.-T. Xu, Prog. Polym. Sci., 2012, 37, 13501400.

5 D. J. Pochan, Z. Chen, H. Cui, K. Hales, K. Qi and K. L. Wooley, Science, 2004, 306, 94-97.

6 Y. Mai and A. Eisenberg, Chem. Soc. Rev., 2012, 41, 59695985.

7 N. P. Truong, J. F. Quinn, M. R. Whittaker and T. P. Davis, Polym. Chem., 2016, 7, 4295-4312.

8 C. J. Mable, R. R. Gibson, S. Prevost, B. E. McKenzie, O. O. Mykhaylyk and S. P. Armes, J. Am. Chem. Soc., 2015, 137, 16098-16108.

9 L. D. Blackman, S. Varlas, M. C. Arno, A. Fayter, M. I. Gibson and R. K. O'Reilly, ACS Macro Lett., 2017, 6, 1263-1267.

10 L. D. Blackman, S. Varlas, M. C. Arno, Z. H. Houston, N. L. Fletcher, K. J. Thurecht, M. Hasan, M. I. Gibson and R. K. O'Reilly, ACS Cent. Sci., 2018, 4, 718-723.

11 S. L. Canning, G. N. Smith and S. P. Armes, Macromolecules, 2016, 49, 1985-2001.

12 B. Charleux, G. Delaittre, J. Rieger and F. D'Agosto, Macromolecules, 2012, 45, 6753-6765.

13 F. D'Agosto, J. Rieger and M. Lansalot, Angew. Chem., Int. Ed., 2019, 59, 2-27.

14 J. Chiefari, Y. K. Chong, F. Ercole, J. Krstina, J. Jeffery, T. P. T. Le, R. T. A. Mayadunne, G. F. Meijs, C. L. Moad, G. Moad, E. Rizzardo and S. H. Thang, Macromolecules, 1998, 31, 5559-5562.

15 D. J. Keddie, Chem. Soc. Rev., 2014, 43, 496-505.

16 S. Perrier, Macromolecules, 2017, 50, 7433-7447.

17 C. J. Ferguson, R. J. Hughes, B. T. T. Pham, B. S. Hawkett, R. G. Gilbert, A. K. Serelis and C. H. Such, Macromolecules, 2002, 35, 9243-9245.

18 C. J. Ferguson, R. J. Hughes, D. Nguyen, B. T. T. Pham, R. G. Gilbert, A. K. Serelis, C. H. Such and B. S. Hawkett, Macromolecules, 2005, 38, 2191-2204.

19 M. Manguian, M. Save and B. Charleux, Macromol. Rapid Commun., 2006, 27, 399-404.

20 J. Rieger, Macromol. Rapid Commun., 2015, 36, 1458-1471.

21 A. M. dos Santos, J. Pohn, M. Lansalot and F. D'Agosto, Macromol. Rapid Commun., 2007, 28, 1325-1332.

22 I. Chaduc, W. J. Zhang, J. Rieger, M. Lansalot, F. D’Agosto and B. Charleux, Macromol. Rapid Commun., 2011, 32, 1270-1276.

23 N. J. Warren and S. P. Armes, J. Am. Chem. Soc., 2014, 136, 10174-10185.

24 J.-T. Sun, C.-Y. Hong and C.-Y. Pan, Polym. Chem., 2013, 4, 873-881.

25 M. J. Derry, L. A. Fielding and S. P. Armes, Prog. Polym. Sci., 2016, 52, 1-18.

26 A. Blanazs, A. J. Ryan and S. P. Armes, Macromolecules, 2012, 45, 5099-5107.

27 E. R. Jones, M. Semsarilar, P. Wyman, M. Boerakker and S. P. Armes, Polym. Chem., 2016, 7, 851-859.
28 L. D. Blackman, K. E. B. Doncom, M. I. Gibson and R. K. O’Reilly, Polym. Chem., 2017, 8, 2860-2871.

29 J. Tan, Y. Bai, X. Zhang and L. Zhang, Polym. Chem., 2016, 7, 2372-2380.

30 E. R. Jones, M. Semsarilar, A. Blanazs and S. P. Armes, Macromolecules, 2012, 45, 5091-5098.

31 M. Semsarilar, N. J. W. Penfold, E. R. Jones and S. P. Armes, Polym. Chem., 2015, 6, 1751-1757.

32 S. J. Byard, M. Williams, B. E. McKenzie, A. Blanazs and S. P. Armes, Macromolecules, 2017, 50, 1482-1493.

33 M. Semsarilar, V. Ladmiral, A. Blanazs and S. P. Armes, Langmuir, 2012, 28, 914-922.

34 I. Chaduc, M. Girod, R. Antoine, B. Charleux, F. D'Agosto and M. Lansalot, Macromolecules, 2012, 45, 5881-5893.

35 I. Chaduc, A. Crepet, O. Boyron, B. Charleux, F. D’Agosto and M. Lansalot, Macromolecules, 2013, 46, 6013-6023.

36 W.-M. Wan, C.-Y. Hong and C.-Y. Pan, Chem. Commun., 2009, 5883-5885.

37 C.-Q. Huang and C.-Y. Pan, Polymer, 2010, 51, 5115-5121.

38 W. Cai, W. Wan, C. Hong, C. Huang and C. Pan, Soft Matter, 2010, 6, 5554-5561.

39 W.-D. He, X.-L. Sun, W.-M. Wan and C.-Y. Pan, Macromolecules, 2011, 44, 3358-3365.

40 S. Boisse, J. Rieger, K. Belal, A. Di-Cicco, P. Beaunier, M. H. Li and B. Charleux, Chem. Commun., 2010, 46, 19501952.

41 S. Boisse, J. Rieger, G. Pembouong, P. Beaunier and B. Charleux, J. Polym. Sci., Part A: Polym. Chem., 2011, 49, 3346-3354.

42 X. L. Fan, X. J. Jia, H. P. Zhang, B. L. Zhang, C. M. Li and Q. Y. Zhang, Langmuir, 2013, 29, 11730-11741.

43 J. L. de la Haye, X. W. Zhang, I. Chaduc, F. Brunel, M. Lansalot and F. D'Agosto, Angew. Chem., Int. Ed., 2016, 55, 3739-3743.

44 J. Tan, X. Dai, Y. Zhang, L. Yu, H. Sun and L. Zhang, ACS Macro Lett., 2019, 8, 205-212.

45 B. T. T. Pham, D. Nguyen, V. T. Huynh, E. H. Pan, B. Shirodkar-Robinson, M. Carey, A. K. Serelis, G. G. Warr, T. Davey, C. H. Such and B. S. Hawkett, Langmuir, 2018, 34, 4255-4263.

46 D. Nguyen, V. Huynh, N. Pham, B. Pham, A. Serelis, T. Davey, C. Such and B. Hawkett, Macromol. Rapid Commun., 2019, 40, 1800402.

47 E. E. Brotherton, F. L. Hatton, A. A. Cockram, M. J. Derry, A. Czajka, E. J. Cornel, P. D. Topham, O. O. Mykhaylyk and S. P. Armes, J. Am. Chem. Soc., 2019, 141, 13664-13675.

48 F. L. Hatton, A. M. Park, Y. R. Zhang, G. D. Fuchs, C. K. Ober and S. P. Armes, Polym. Chem., 2019, 10, 194200.

49 X. Dai, L. Yu, Y. Zhang, L. Zhang and J. Tan, Macromolecules, 2019, 52, 7468-7476.

50 N. P. Truong, M. V. Dussert, M. R. Whittaker, J. F. Quinn and T. P. Davis, Polym. Chem., 2015, 6, 3865-3874.

51 W. J. Zhang, F. D’Agosto, O. Boyron, J. Rieger, B. Charleux, F. D'Agosto, O. Boyron, J. Rieger and B. Charleux, Macromolecules, 2011, 44, 7584-7593. 
52 L. Carlsson, A. Fall, I. Chaduc, L. Wagberg, B. Charleux, E. Malmstrom, F. D’Agosto, M. Lansalot and A. Carlmark, Polym. Chem., 2014, 5, 6076-6086.

53 F. L. Hatton, M. Ruda, M. Lansalot, F. D’Agosto, E. Malmstrom and A. Carlmark, Biomacromolecules, 2016, 17, 1414-1424.

54 J. Rieger, F. Stoffelbach, C. Bui, D. Alaimo, C. Jerome and B. Charleux, Macromolecules, 2008, 41, 4065-4068.

55 J. Engström, F. L. Hatton, L. Wågberg, F. D’Agosto, M. Lansalot, E. Malmström and A. Carlmark, Polym. Chem., 2017, 8, 1061-1073.

56 J. Rieger, G. Osterwinter, C. O. Bui, F. Stoffelbach and B. Charleux, Macromolecules, 2009, 42, 5518-5525.

57 V. J. Cunningham, A. M. Alswieleh, K. L. Thompson, M. Williams, G. J. Leggett, S. P. Armes and O. M. Musa, Macromolecules, 2014, 47, 5613-5623.

58 B. Akpinar, L. A. Fielding, V. J. Cunningham, Y. Ning, O. O. Mykhaylyk, P. W. Fowler and S. P. Armes, Macromolecules, 2016, 49, 5160-5171.

59 L. H. Guo, Y. J. Pang, T. Qiu, Y. Meng and X. Y. Li, Polymer, 2014, 55, 4601-4610.

60 X. Zhang, S. Boissé, W. Zhang, P. Beaunier, F. D’Agosto, J. Rieger and B. Charleux, Macromolecules, 2011, 44, 41494158.

61 W. J. Zhang, F. D’Agosto, O. Boyron, J. Rieger and B. Charleux, Macromolecules, 2012, 45, 4075-4084.

62 A. A. Cockram, T. J. Neal, M. J. Derry, O. O. Mykhaylyk, N. S. J. Williams, M. W. Murray, S. N. Emmett and S. P. Armes, Macromolecules, 2017, 50, 796-802.

63 L. P. D. Ratcliffe, A. J. Ryan and S. P. Armes, Macromolecules, 2013, 46, 769-777.

64 F. L. Hatton, J. R. Lovett and S. P. Armes, Polym. Chem., 2017, 8, 4856-4868.

65 P. Chambon, A. Blanazs, G. Battaglia and S. P. Armes, Langmuir, 2012, 28, 1196-1205.

66 N. J. W. Penfold, Y. Ning, P. Verstraete, J. Smets and S. P. Armes, Chem. Sci., 2016, 7, 6894-6904.

67 J. Tan, D. Liu, C. Huang, X. Li, J. He, Q. Xu and L. Zhang, Macromol. Rapid Commun., 2017, 38, 1700195.

68 X. Dai, Y. Zhang, L. Yu, X. Li, L. Zhang and J. Tan, ACS Macro Lett., 2019, 8, 955-961.

69 Q. Xu, Y. Zhang, X. Li, J. He, J. Tan and L. Zhang, Polym. Chem., 2018, 9, 4908-4916.
70 J. Ilavsky and P. R. Jemian, J. Appl. Crystallogr., 2009, 42, 347-353.

71 A. Blanazs, J. Madsen, G. Battaglia, A. J. Ryan and S. P. Armes, J. Am. Chem. Soc., 2011, 133, 16581-16587.

72 L. A. Fielding, M. J. Derry, V. Ladmiral, J. Rosselgong, A. M. Rodrigues, L. P. D. Ratcliffe, S. Sugihara and S. P. Armes, Chem. Sci., 2013, 4, 2081-2087.

73 L. A. Fielding, J. A. Lane, M. J. Derry, O. O. Mykhaylyk and S. P. Armes, J. Am. Chem. Soc., 2014, 136, 5790-5798.

74 M. Semsarilar, E. R. Jones, A. Blanazs and S. P. Armes, Adv. Mater., 2012, 24, 3378-3382.

75 I. Bannister, N. C. Billingham, S. P. Armes, S. P. Rannard and P. Findlay, Macromolecules, 2006, 39, 7483-7492.

76 J. S. Pedersen, J. Appl. Crystallogr., 2000, 33, 637-640.

77 O. Glatter and O. Kratky, Small-angle X-ray Scattering, Academic Press, London, 1982.

78 J. Bang, S. M. Jain, Z. B. Li, T. P. Lodge, J. S. Pedersen, E. Kesselman and Y. Talmon, Macromolecules, 2006, 39, 1199-1208.

79 Y. Zhang, L. Yu, X. Dai, L. Zhang and J. Tan, ACS Macro Lett., 2019, 8, 1102-1109.

80 X. Li, J. Tan, Q. Xu, J. He and L. Zhang, Macromol. Rapid Commun., 2018, 39, 1800473.

81 J. R. Lovett, L. P. D. Ratcliffe, N. J. Warren, S. P. Armes, M. J. Smallridge, R. B. Cracknell and B. R. Saunders, Macromolecules, 2016, 49, 2928-2941.

82 N. J. W. Penfold, A. J. Parnell, M. Molina, P. Verstraete, J. Smets and S. P. Armes, Langmuir, 2017, 33, 14425-14436.

83 C. György, J. R. Lovett, N. J. W. Penfold and S. P. Armes, Macromol. Rapid Commun., 2018, 1800289.

84 B. Hammouda, Probing Nanoscale Structures - The SANS Toolbox, National Institute of Standards and Technology, Gaithersburg, 2008.

85 J. B. Hayter and J. Penfold, Mol. Phys., 1981, 42, 109118.

86 S. J. Tseng, C. C. Chien, Z. X. Liao, H. H. Chen, Y. D. Kang, C. L. Wang, Y. Hwu and G. Margaritondo, Soft Matter, 2012, 8, 1420-1427.

87 M. H. Qiao, F. Q. Yan, W. S. Sim, J. F. Deng and G. Q. Xu, Surf. Sci., 2000, 460, 67-73.

88 M. J. Derry, L. A. Fielding, N. J. Warren, C. J. Mable, A. J. Smith, O. O. Mykhaylyk and S. P. Armes, Chem. Sci., 2016, 7, 5078-5090. 